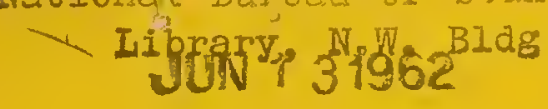

NBS MONOGRAPH 48

\title{
Determination of Total X-Ray Beam Energy With a Calibrated Ionization Chamber
}

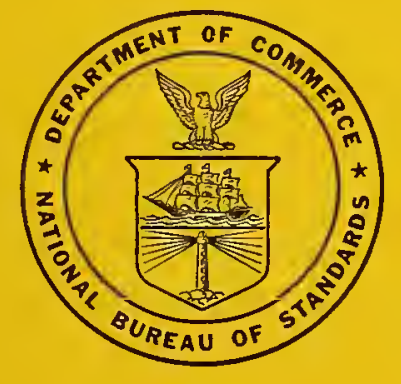

U.S. DEPARTMENT OF COMMERCE

NATIONAL BUREAU OF STANDARDS 


\section{THE NATIONAL BUREAU OF STANDARDS}

\section{Functions and Activities}

The functions of the National Bureau of Standards are set forth in the Act of Congress, March 3, 1901, as amended by Congress in Public Law 619, 1950. These include the development and maintenance of the national standards of measurement and the provision of means and methods for making measurements consistent with these standards; the determination of physical constants and properties of materials; the development of methods and instruments for testing materials, devices, and structures; advisory services to government agencies on scientific and technical problems; invention and development of devices to serve special needs of the Government; and the development of standard practices, codes, and specifications. The work includes basic and applied research, development, engineering, instrumentation, testing, evaluation, calibration services, and various consultation and information services. Research projects are also performed for other government agencies when the work relates to and supplements the basic program of the Bureau or when the Bureau's unique competence is required. The scope of activities is suggested by the listing of divisions and sections on the inside of the back cover.

\section{Publications}

The results of the Bureau's research are published either in the Bureau's own series of publications or in the journals of professional and scientific societies. The Bureau itself publishes three periodicals available from the Government Printing Office: The Journal of Research, published in four separate sections, presents complete scientific and technical papers; the Technical News Bulletin presents summary and preliminary reports on work in progress; and Basic Radio Propagation Predictions provides data for determining the best frequencies to use for radio communications throughout the world. There are also five series of nonperiodical publications: Monographs, Applied Mathematics Series, Handbooks, Miscellaneous Publications, and Technical Notes.

A complete listing of the Bureau's publications can be found in National Bureau of Standards Circular 460, Publications of the National Bureau of Standards, 1901 to June 1947 (\$1.25), and the Supplement to National Bureau of Standards Circular 460, July 1947 to June 1957 (\$1.50), and Miscellaneous Publication 240, July 1957 to June 1960 (Includes Titles of Papers Published in Outside Journals 1950 to 1959) (\$2.25); available from the Superintendent of Documents, Government Printing Office, Washington 25, D.C. 
UNITED STATES DEPARTMENT OF COMMERCE - Luther H. Hodges, Secretary NATIONAL BURFAU OF STANDARDS • A. V. Astin, Director

\section{Determination of Total X-Ray Beam Energy}

\section{With a Calibrated Ionization Chamber}

John S. Pruitt and Steve R. Domen

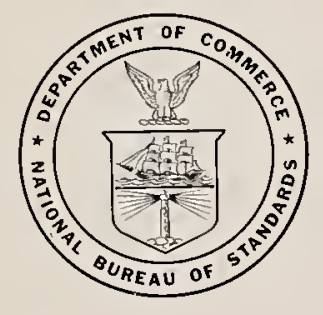

National Bureau of Standards Monograph 48

Issued June 5, 1962 


\section{Contents}

1. Introduction _......... Pare

2. Description of the P2 chamber $\ldots \ldots \ldots \ldots$

3. Use of the P2 chamber $\ldots \ldots \ldots \ldots \ldots \ldots$

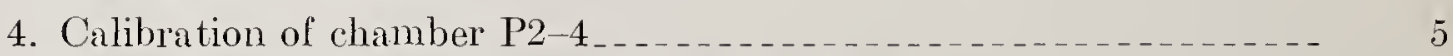

5. Sensitivity of P2-4 to monoenergetic photons $\ldots \ldots \ldots \ldots$

6. Variations of the P2 calibration

7. References 


\title{
Determination of Total X-Ray Beam Energy With a Calibrated Ionization Chamber*
}

\author{
John S. Pruitt and Steve R. Domen
}

\begin{abstract}
This report describes the use of an air-filled aluminum-alloy ionization chamber to determine the energy transported by a bremsstrahlung beam with maximum photon energy in the range 6 to $170 \mathrm{Mev}$. The experimental calibrations of this chamber over this energy range are given, as well as the results of calibration experiments made with a $250-\mathrm{kv}$ constantpotential $\mathrm{X}-1$ ay tube and with $\mathrm{Cs}^{137}$ and $\mathrm{Co}^{60}$ gamma-rays. Information is presented about the change in calibration when the chamber is used with different experimental conditions, and when either its dimensions or its alloy composition are changed slightly. This report can be used to construct a replica chamber and to determine its absolute calibration between 6 and $170 \mathrm{Mev}$ under a variety of experimental conditions.
\end{abstract}

\section{Introduction}

The proper evaluation of most experiments performed with a betatron or synchrotron X-ray beam requires knowledge of the absolute number of incident photons of each energy. This knowledge can be obtained by calculating the relative spectral intensity distribution as a function of photon energy, which can be predicted theoretically with reasonable accuracy $[1],{ }^{1}$ and determining the total beam energy with a calibrated monitor. This energy is proportional to the area under the spectral distribution curve, and can be used to assign absolute values to the distribution at each photon energy.

The proper calibration of the beam monitor is an important task in most radiation experiments, where the accuracy of the results depends upon the accuracy with which the incident energy is known. Several different techniques for performing this task have been described, relying either upon theoretical descriptions of the interaction of X-rays with matter, or upon experimental energy measurements [2]. The theoretical descriptions require knowledge of atomic parameter's which are not accurately known for highenergy bremsstrallung beams, such as average electronic stopping powers, but the experimental techniques of bean energy measurement have now been developed to the point where a monitor can be calibrated experimentally to within a few percent.
This report concerns the experimental method used in the High Energy Radiation Section of the National Bureau of Standards for rapid and accurate calibration of X-ray monitors for beams with maximum photon energy between $E_{\max }=6$ and $E_{\mathrm{max}}=170 \mathrm{Mev}$. The method is based upon results obtained in a series of experiments [3], performed with two instruments which determine the total beam energy in absolute units, a refined version of the lead calorimeter described by Laughlin and Beattie [4], and a large scintillation crystal [5].

These absolute beam-energy measurements were used to calibrate an ionization chamber of a type labeled P2, so that a measurement of the ionization charge collected during an X-ray exposure determines the total beam energy incident on the front face of the chamber. 'This chamber has been classified as a Standard Instrument, and its calibration is expressed as the energy in joules required to produce one coulomb of ionization charge inside the chamber when it contains dry air at $20^{\circ} \mathrm{C}$ and a pressure of $760 \mathrm{~mm}$ of mercury. The calibrated chamber is used in this laboratory either to transfer the absolute calibration to special monitors used in radiation experiments, or as a continuous-duty monitor in cases where its large dimensions are not inconvenient.

\section{Description of the P2 Ghamber}

Detailed shop drawings of the P2 chamber accompany this Monograph (figs. 17, 18, 19), but its principal features, the thick front wall and the multicellular ionization-collection assembly, are shown in the schematic cross section of figure 1 and the photographs of figures 2 and 3 . These chambers were designed for use in $\mathrm{X}$-ray beams up to $20 \mathrm{~cm}$ in diameter and with intensities ranging

*This work was supported in part by the A tomic Energy Commission.

*This work was supported in part by the A tomic Energy Commission. 1 Figures in
Monograph. from 0.5 to $1,000 \mu \mathrm{w} / \mathrm{cm}^{2}$. The manner in which the design was affected by these criteria is de. scribed below.

The diameter of the chamber was chosen to be large both to allow its use with large-diameter $\mathrm{X}$-ray beans and to reduce the dependence of the calibration on beam diameter. The calibration depends on the size of the beam becanse a part of the radiation scattered in the thick front wall misses the air cavity, and the fraction escaping increases with increasing bean dimeter. The 
diameter of the internal plates is $29.2 \mathrm{~cm}$, large enough so that the calibration decreases by no more than 0.1 percent as the beanl diameter increases from 0 to $4 \mathrm{~cm}$, and by no more than 3 percent for an increase to $20 \mathrm{~cm}$.

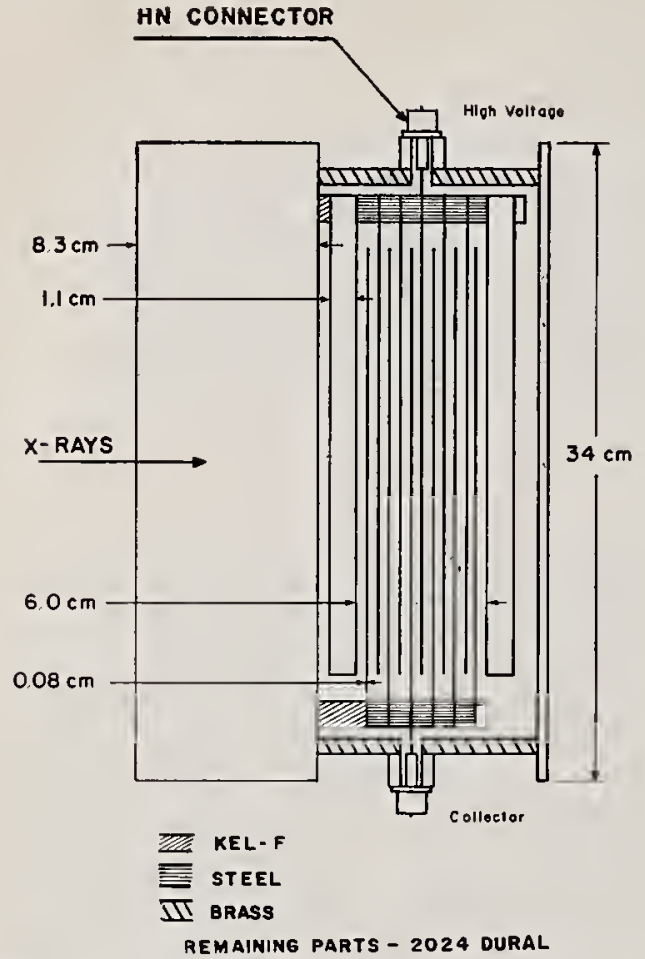

Figure 1. Schematic cross section of a P2 chamber.

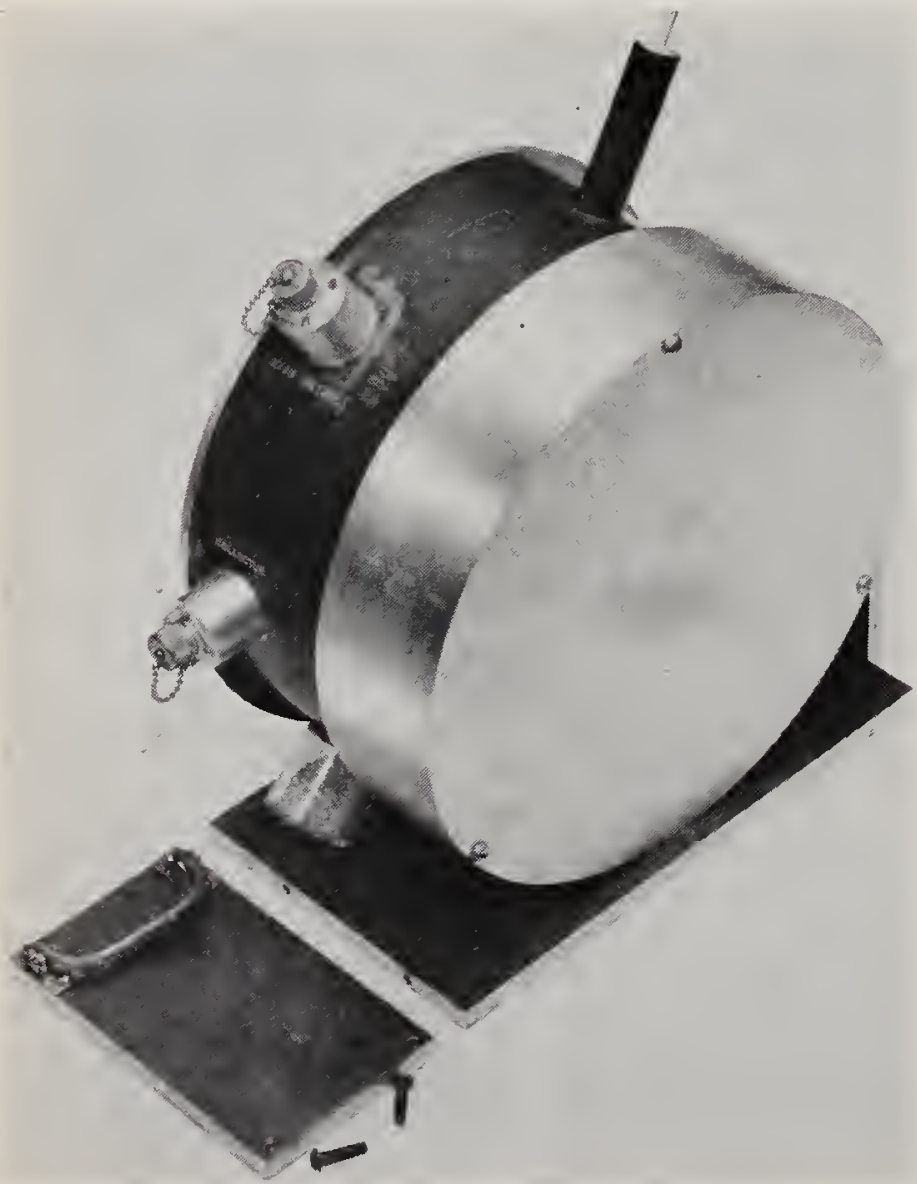

Figure 2. External view of a P2 chamber.
The front wall is made of 2024 Dural, an aluminum alloy whose composition is shown in table 1. Its thickness was chosen to minimize the dependence of the calibration, joules/coulomb, on the maximum photon energy of the bremsstrahlung beam. The calibration depends on the maximum photon energy because it is a function of the spectral distribution of the incident photons, which changes with the maximum energy. The spectral distribution is also a function of the beam filtration, so although it is possible to minimize the variation with maximum energy for a given filtration, there is no choice which will make this variation small for all filters. The thickness chosen is $9.4 \mathrm{~cm}$, which reduces this

TABLE 1. Composition of 2024 Dural a

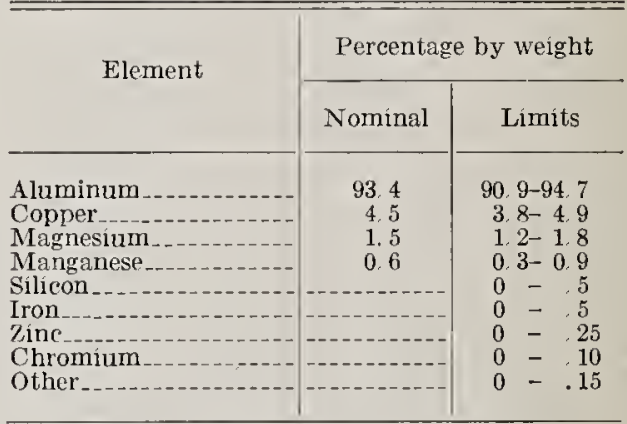

a This alloy was ealled $24 \mathrm{~S}$ Dural prior to 1954

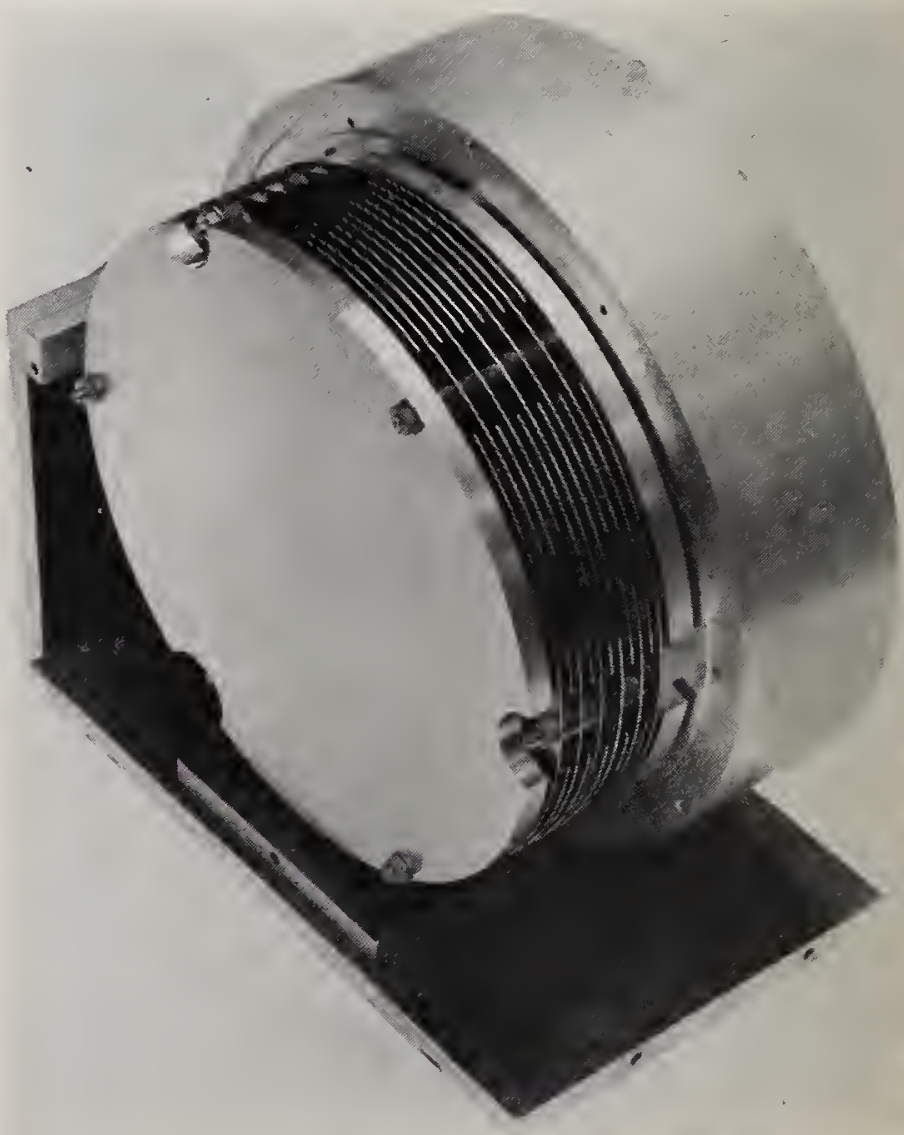

FIGURE 3. Ionization-collection assembly of a PQ chamber. 
variation to 10 percent between 6 and $170 \mathrm{Mev}$, with a filtration of $4.5 \mathrm{~g} / \mathrm{cm}^{2}$ of aluminum. ${ }^{2}$

The internal plate assembly, where ionization is produced and collected, contains dry air at atmospheric pressure. It was designed to have high sensitivity and low leakage, so that it could be used with low-intensity beams, and a small probability for ion recombination, so that it could also be used with high-intensity beams. These divergent requirements were met by using a thick air cavity $(5 \mathrm{~cm})$, divided into 12 segments by thin Dural plates. These are alternately high-voltage and collector plates, mounted in two interleaved stacks. The two outer plates are high-voltage plates, and are considerably heavier than the inner plates. The plates within each stack are separated by ground steel spacers, which serve to connect them electrically. Each stack is mounted on Kel-F insulator's, which are in turn mounted on the grounded front cover, so that there is no direct leakage path between the two stacks. This style of construction insures that the total thickness of the air cavity remains fixed, and that the calibration will not change even if the assembly is dismantled and reassembled. 'These advantages, plus the relative compactness of the P2 chamber, are the reasons this design was chosen in preference to the design of Wilson [6], where ionization is sampled at several depths in an absorbing medium of essentially infinite thickness.

\section{Use of the P2 Chamber}

Figure 4 is a schematic diagram of the experimental arrangement during a typical calibration transfer from a P2 chamber to a thin-walled monitor used with the 180-Mev synchrotron. $\mathrm{X}$-rays incident on the $\mathrm{P} 2$ chamber are filtered by one wall of the donut (the evacuated electronacceleration tube) and the monitor. The size and shape of the direct beam in such an arrangement are determined by the aperture in the main lead shield, but radiation scattered in the main shield, the monitor walls, and the air adds a second, more divergent component to the beam. The auxiliary lead shields shown in figure 4 were inserted to reduce the spurious effects produced by this second component. 'The one in front of the monitor reduced its response to this scattered component, a precaution which increased the reliability of the monitor calibration, since it has

2 If the ehamber is used with a different filter, or at maximum energies outside this range, the variation of the ealibration with peak energy may be outside this range, the variation of the ealibration with peak energy may be
large in the region of interest. It ean usually be reduced over a limited range by ehanging the front-wall thiekness. been found that the secondary to primary intensity ratio is a function of changes in operating conditions. $^{3} \quad$ The auxiliary shield behind the monitor guards against backscattered radiation.

The auxiliary shield in front of the P2 chamber served to limit the fraction of this scattered component incident on the chamber. In this particular experiment, it was necessary to know the amount of radiation energy incident on an area $9 \mathrm{~cm}$ in diameter and $70 \mathrm{~cm}$ behind the monitor. The P2 chamber was mounted with its front face at this position with a 9-cm-diam hole in the lead shield in front of it. The beam was only $4.2 \mathrm{~cm}$ in diameter at this position, but this technique included a 9-cm-dian scattered-

\footnotetext{
3 For instance, the monitor response, per unit energy in the direct beam, increases by about 3 pereent when the synchrotron donut air pressure increases from $6 \times 10^{-6}$ to $35 \times 10^{-6} \mathrm{~mm}$ of mereury. This is caused by an inerease in the relative number of seeondary electrons from the main shiclding aperture, which is in turn caused by an inerease in the size of the X-ray source. A sizable fraction of the monitor response (of the order of 50 pereent) is caused by these seattered eleetrons, so it will change when the relative electronintensity ehanges. The P2 response is mucl less affected by these electrons, although it is affected by scattered photons, as discussed in the text.
}

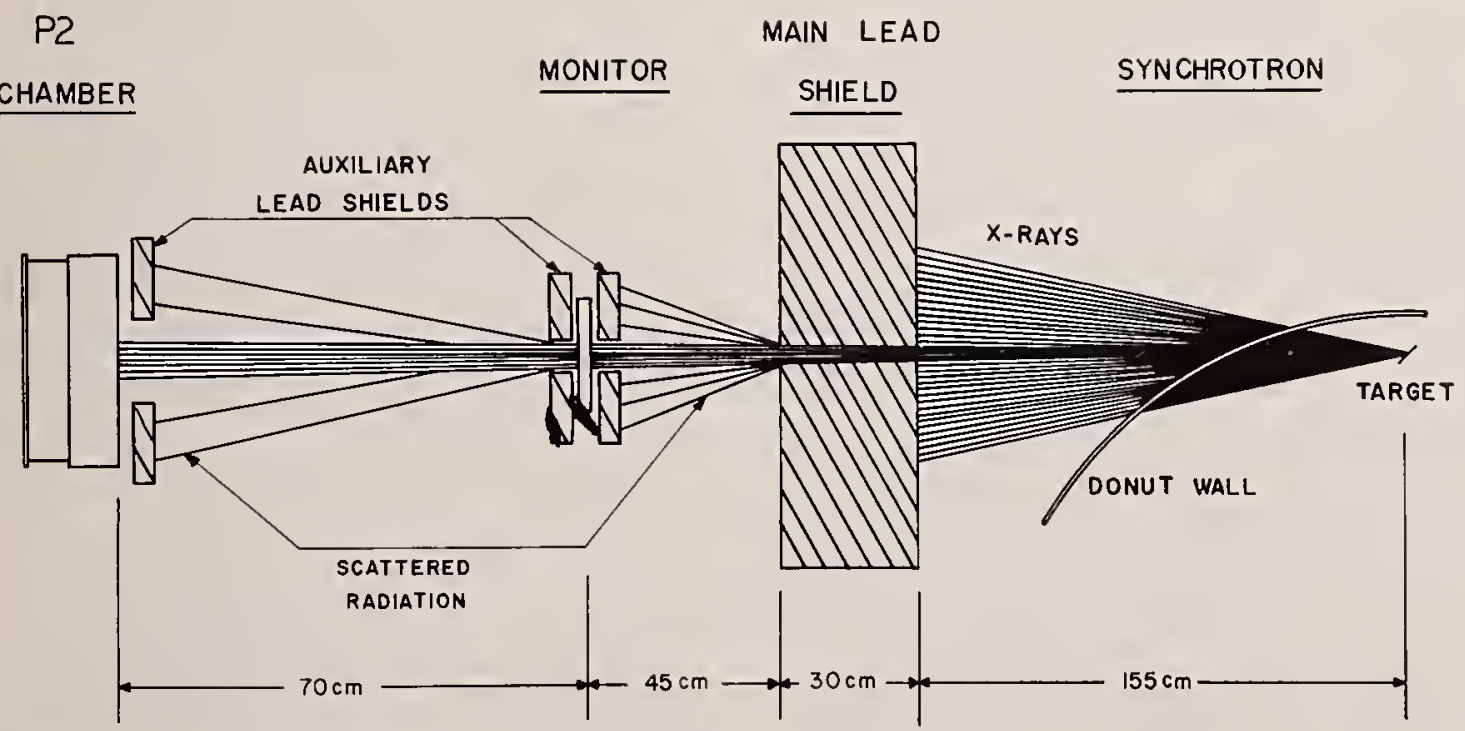

Figure 4. Experimental arrangement during a typical monitor calibration. 


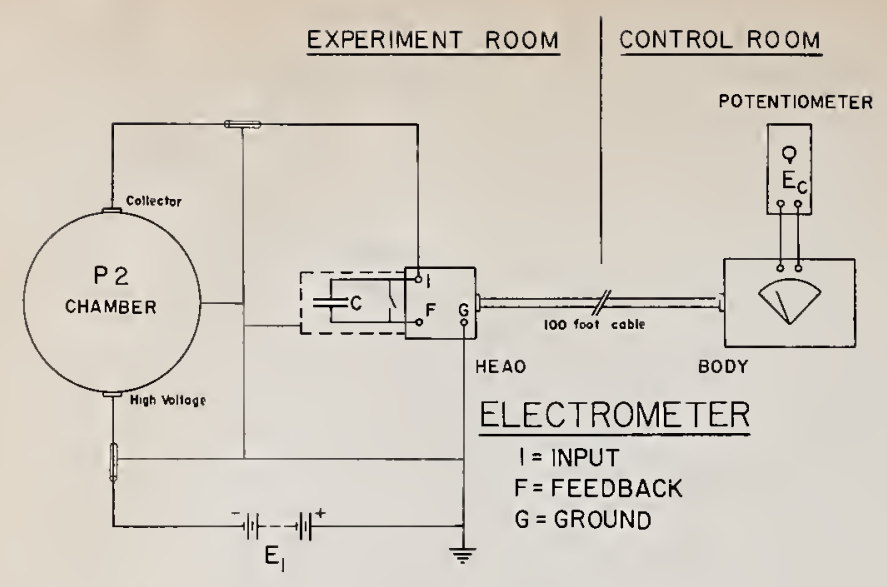

FIGURE 5. Electical circuit used for ionization-charge measurement.

photon beam in the energy deternination. 'The need to consider this secondary beam decreases as the distance between P2 and the monitor increases, but at the small separation shown in figure 4 , the secondary bean may contribute as much as 1 percent to the energy incident on the P2 chamber. Although this scattered component has been slightly degraded in energy, the chamber calibration varies too slowly with energy to be noticeably changed by this degradation.

The ionization charge collected in the P2 chamber during an X-1ay exposure is measured with the modified Townsend balance circuit shown in figure 5. The required components are a high-quality polystyrene capacitor, $C$, a stable source of high voltage, $E_{I}$, a slide-wire potentiometer which is used as a source of compensating voltage, $E_{C}$, and a vibrating reed electrometer. Coaxial cables with a solid polyethylene dielectric are used to connect the P2 chamber to the power supply and to the electrometer. The electrometer cable is of the lownoise variety, with a semiconductor coating on the dielectric.

The electrometer used in this laboratory is a three-terminal model divided into two components, which are mounted in separate rooms and connected by a 100-ft cable. The head of the electrometer is mounted in the experiment room close to the P2 chamber, to reduce the length of the input cable. The head contains two amplifier tubes and supports a grounded metal box covering the external capacitor, $C$, which must be carefully shielded against stray radiation. $C$ is mounted between the input and feedback terminals of the electrometer, in parallel witl a small internal capacitor, $C^{\prime}$ (about $10 \mathrm{pl} \mathbf{f}^{\prime}$ ). The amplified signal enters the main body of the electrometer through the 100-ft cable. This component contains most of the electronic circuitry, the zeroing controls, range selector, and output meter. It is located in the accelerator control room, where the calibration data are recorded.

The potentiometer is a commercial $1.6-\mathrm{v}$ model, constructed so that it can be periodically and easily calibrated with a self-contained standard cell. It is connected in series with the electrometer feedback loop by means of an external connector on the electrometer. It is used as a source of accurately known voltage, which can be conveniently varied from $E_{C}=0$ to $E_{C}=1.6 \mathrm{v}$.

The source of high voltage, $E_{I}$, is a battery power supply consisting of $67.5-\mathrm{v}$ dry cells connected in series. They are mounted in a temperatureregulated box to reduce the electrometer drift currents caused by changes in the ambient temperature. A total of $1,200 \mathrm{v}$ is normally used with high-intensity X-ray beams in this laboratory. This voltage is large enough to reduce the error caused by ion recombination to about 0.1 percent with a synchrotron beam intensity ${ }^{4}$ of 400 $\mu \mathrm{w} / \mathrm{cm}^{2}$. 'This was determined by plotting the measured ratio $E_{C} /$ monitor-volt as a function of the ratio relative-intensity $/ E_{I}$, and making a linear extrapolation to zero intensity [7].

Values of $E_{I}$ as large as 2,200 v have been used with no evidence of gas multiplication, but the electrometer drift currents were too large for convenient operation. With $E_{I}=1,200 \mathrm{v}$, this drift current is normally less than $10^{-13}$ amp. Larger currents signily direct leakage between the electrodes, which is usually caused by lint in the air cavity. This can often be corrected by removing the plate assembly and blowing it out with a high-pressure jet of nitrogen, but on occasion it is necessary to dismantle and clean the components to achieve a difit current as small as this.

When the P2 chamber is used with low-intensity X-ray beams, recombination problems are less severe, and $E_{I}=800 \mathrm{v}$ is usually used. This reduces the chamber leakage, and electrometer drift currents of the order of $10^{-14}$ amp are typical.

The electrometer is always used as a null instrument rather than as a deflection instrument, so that accurate charge measurements can be made without knowing the leakage capacitances to ground or the absolute electrometer calibration. With the compensating voltage $E_{C}=0, C$ is discharged with the shorting switch before an X-ray exposure. The electrometer is then zeroed on a sensitive scale and the exposure begun. During exposure, the electrometer needle may be kept on scale either by continuously increasing $E_{C}$ or by switching to a less sensitive scale.

After an exposure has been completed, the needle is returned to its initial position by adjusting $E_{C}$. The ionization charge collected in the P2 chamber during the exposure can be calculated from the equation

$q($ coulomb $)=[C$ (farad $)+C^{\prime}($ farad $\left.)\right] \times E_{C}($ volt $)$,

where $C$ and $C^{\prime}$ are the capacitances of the external and internal capacitors in the electrometer head

\footnotetext{
4 The synelirotron produces $60 \mathrm{I}$-ray pulses per second, and with this intensity, each pulse produces an ionization density of about $2 \times 10^{-12}$ cou lombs $/ \mathrm{cm}^{3}$.
} 
and $E_{C}$ is the compensating voltage required to l'eturn the electrometer needle to its initial position. $E_{C}$ can be obtained directly from the calibrated potentiometer, and $\left(C+C^{\prime}\right)$ can be determined by the d-c comparison method described below.

Absolute knowledge of $\left(C+C^{\prime}\right)$ can be obtained with the equipment of figure 5, plus a standard air capacitor of known capacitanee, $C_{S}$, and a second potentiometer used as a variable source of voltage, $E_{S}$. The comparison eireuit is similar to that of figure 5, except that the $\mathrm{P} 2$ chamber is replaced by $C_{S}$ and the high-voltage supply by $E_{S}$, to form a simple series loop between terminal $I$ and ground. The polarity of $E_{S}$ must be such that an increase of $E_{S}$ will move the electrometer necdle in the opposite direction from that caused by an increase of $E_{C}$. The measurement is made by first zeroing the electrometer needle with the condenser's discharged and $E_{C}=E_{S}=0$, and then determining the value of one (say $E_{S}$ ) required to return the needle to its initial position after the other $\left(E_{C}\right)$ has been changed. 'Then

$$
C+C^{\prime}=\frac{E_{S}}{E_{C}} C_{S}
$$

and $\left(C+C^{\prime}\right)$ is known in terms of $C_{S}{ }^{5}{ }^{5}$

'The P2 chamber can itself be used as a continuous-duty exposure monitor, or it can be used to ealibrate a different monitor, as in the situation shown in figure 4 . 'The auxiliary monitors used in this laboratory are usually transmission-ionization chamber's, of the general type shown in figure 6 . This is a thin-walled chamber lor use in relatively high-intensity beams. The walls and air gaps as shown are thin enough to prevent

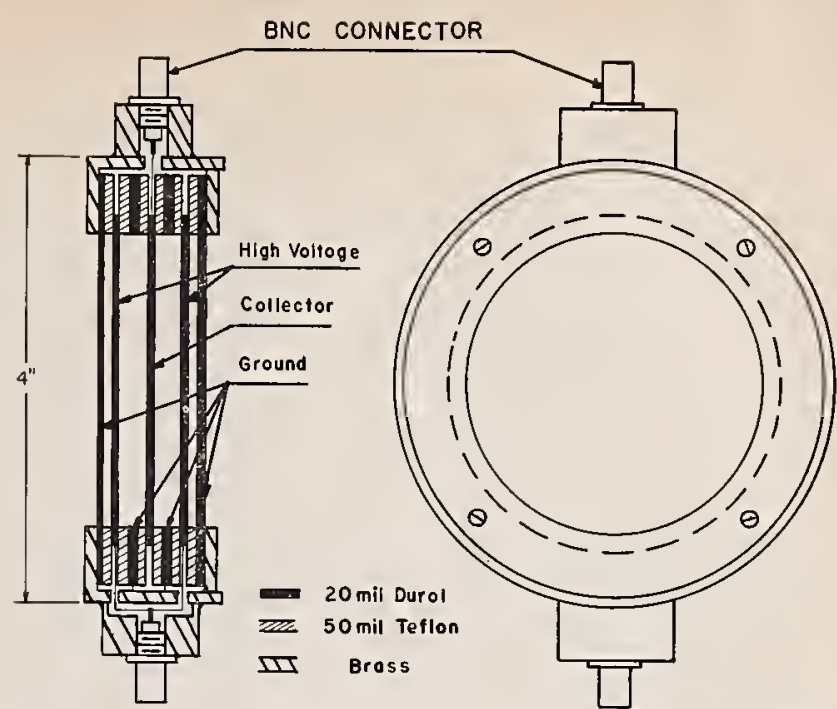

Frgure 6. Schematic cross section of an ionizationchamber monitor.

noticcable ion reeombination in the $\mathrm{X}$-ray beams used in this laboratory, but if the charge liberated per pulse of X-rays is larger in another laboratory, the recombination probability may increase chough to make even smaller dimensions mandatory. ${ }^{6}$ 'The high voltage normally used with this type of monitor is about $150 \mathrm{v}$.

Tonitor voltage measurements are always made with the same type of circuit as that shown in figure 5 for the $\mathrm{P} 2$ chamber, so that the transler of a P2 calibration to a transmission chamber requires two dectrometer's and additional capacitol's. 'The monitor' calibration can be expressed in joules/monitor-volt, so that there is no need for absolute knowledge of the capacitanees used with the monitor.

\section{Calibration of Chamber P2-4}

The ionization eharge collected in a P2 chamber is related to the incident radiation energy by

$$
\begin{aligned}
\text { Energy (joules })= & q(\text { coulombs }) \\
& \times \text { Cal (joules/coulomb) }
\end{aligned}
$$

where $q$ (coulombs) is the measured ionization charge and Cal (joules/eoulomb) is the chamber calibration, a number which varies with maximum photon enclgy. One of the NBS chamber's, P2-4, has been calibrated in bremsstrahlung beams between 6 and $170 \mathrm{Mev}$ in a scries of four experiments performed with the two NBS eircular electron accelerators, a $50-\mathrm{Mev}$ betatron, and a 180-Nev synchrotron. Each experiment consisted of two measurements at a variety of maximum energies. The first part was a determination of the ionization charge collected in a

5 Alternate-current measurement of $\left(C+C^{\prime}\right)$ will not give the proper value to use in eq (1) if these capaeitors are not air dielectrie. For polystyrene capacitors, measurements at $1,000 \mathrm{e} / \mathrm{s}$ underestimate the capaeitance by as mueh as several tenths of one pereent. Alternate-current measurements aid mueh as several tenths of one pereent. Alternate-current measuremmis aro the effeets of capacities to ground.
P2 chamber per unit monitor response, using all experimental arrangement similar to that of figure 4. The seeond part was a determination of the total incident beam energy per unit monitor response, and was performed by replacing the P2 chamber by an absolute cnergy-measuring instrument.

These four experiments are compared in table 2. The first experiment was performed with a seintillating crystal [5], covering the energy range between 20 and $170 \mathrm{Mev}$. The next two experiments were performed with a calorimeter [3], between 18 and $42 \mathrm{Mev}$ and between 20 and 170 Mev, respectively. Experiment 4 was perlorned with a crrstal [3] to investigate energies between 6 and $19 \mathrm{Nev}$, a region of great importance to nuclear physies, but one where the intensities of the NBS accelerators were too small for" calorimeter measurements. 'The data from experiment

6 Acerding to the theory presented in reference [7], the probability of recombination is a function of tho charge liberated per pulse, which onn be taken as proportional to the ratio of the time arerage X-ray infensity to the pulse repefition rate. 
TABLE 2. ITigh-energy calibration experiments

\begin{tabular}{|c|c|c|c|c|}
\hline Experiment No. & 1 & 2 & 3 & 4 \\
\hline Date of experimcnt..... & $195 \bar{\imath}$ & 1958 & 1959 & 1959 \\
\hline Participants... & $\left\{\begin{array}{l}J_{\text {. E. Leiss }} \\
R_{\text {. A. Schraek }}\end{array}\right.$ & $\begin{array}{l}\text { J. S. Pruitt } \\
\text { S. R. Domen-- }\end{array}$ & $\begin{array}{l}\text { J. S. Pruitt... } \\
\text { S. R. Domen.- }\end{array}$ & $\begin{array}{l}\text { E. G. Fuller } \\
\text { E. Hayward }\end{array}$ \\
\hline Aceelerator & synchrotron & betatron. & synehrotron & betatron \\
\hline Target material .................. & tungsten & tungsten & tungsten & tungsten \\
\hline Energy range................ & $20-170$ & $18-42$ & $20-170$ & $6-19$ \\
\hline Apparatus. & erystal $\ldots \ldots$ & ealorimeter.... & calorimeter.-.- & erystal \\
\hline Beam diameter & 1.5 & 4.2 & 4. 2 & 5.5 \\
\hline
\end{tabular}

1 vielded a calibration eurve with an estimated error of \pm 3 pereent, that from experiments 2 and 3 a eurve with an estimated error of \pm 2 percent, and the data of experiment 4 has been assigned an error of \pm 2 pereent. 'These error's are not maximum errors, but they are all considerably more eonservative than probable errors. In the calorimeter experiments, for example, both the net systematie error (the square root of the sum of the squares of six different systematic errors) and the standard deviation of the mean of the ealorimeter measurements at each energy were of the order of 0.5 pereent. The quoted \pm 2 pereent error was obtained by adding the former to three times the latter.

The calibrations of P2-4 obtained in these four experiments are listed in table 3 and plotted in figure 7 . They are in good agreement where the energy ranges overlap, exeept at high energies. Even in this region, however, they agree to within the stated errors except at $110 \mathrm{Mev}$. They have all been eorrected to refer to the beam size and filtration used in experiment $3,4.2 \mathrm{~cm}$ diam and $4.5 \mathrm{~g} / \mathrm{cm}^{2}$ of alumimum, ${ }^{7}$ using data presented in section 6 . These eorrections were larger than 0.2 percent only for experiment 4 , and the maximum was 1.0 percent at $6 \mathrm{Mev}$.

The solid curve in figure 7 is considered a best fit to the experimental points (the signifieance of

7 The filtration in eaeh experiment included a donut wall, $4.1 \mathrm{~g} / \mathrm{em}^{2}$ of Pyrex for the synchrotron, and $1.6 \mathrm{~g} / \mathrm{cm}^{\circ}$ of eeramic for the betatron. Caleulations have shown that the filtration eorreetions are ehanged by less than 0.1 percent if the donut wall is treated as an cquivalent $\mathrm{g} / \mathrm{em}^{2}$ of aluminum.

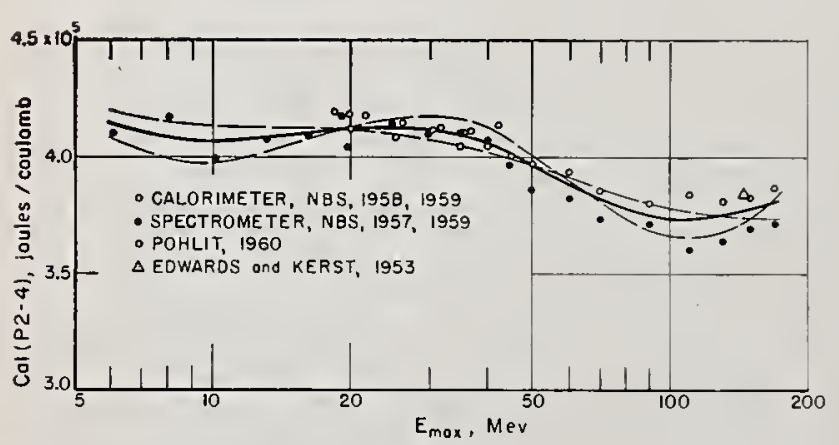

Figure 7. P2-4 calibration at $20{ }^{\circ} \mathrm{C}$ and $760 \mathrm{~mm}$ of mercury in a 4.2-cm-diam bremsstrahlung beam filtered by $4.5 \mathrm{~g} / \mathrm{cm}^{2}$ of aluminum.

The solid curve is a best fit to the experimental data, and the dashed curves are postulated extremes in the shape of the curve.
TABLE 3. Absolute calibrations of chamber $P 2-4$ in a $4.2-$ $\mathrm{cm}$-diam $\mathrm{I}$-ray beam filtered by $4.5 \mathrm{~g} / \mathrm{cm}^{2}$ of aluminum, at $20^{\circ} \mathrm{C}$ and $760 \mathrm{~mm}$ of mercury

\begin{tabular}{|c|c|c|c|}
\hline \multicolumn{2}{|c|}{ Crystal experiments } & \multicolumn{2}{|c|}{ Calorimeter experiments } \\
\hline $\begin{array}{l}\text { Maximum } \\
\text { energy }\end{array}$ & $\mathrm{CaI}\left(\mathrm{P}^{2} 2-4\right)$ & $\underset{\text { cnergy }}{\text { Maximum }}$ & $\mathrm{Cal}(\mathrm{P} 2-4)$ \\
\hline \multicolumn{2}{|c|}{ Experiment 1} & \multicolumn{2}{|c|}{ Experiment 2} \\
\hline \multirow{4}{*}{$\begin{array}{r}1 Y e v \\
19.6 \\
24.6 \\
29.6 \\
34.6 \\
39.6 \\
44.7 \\
49.7 \\
59.7 \\
69.8 \\
89.8 \\
109.9 \\
130.0 \\
150.1 \\
170.2\end{array}$} & \multirow{4}{*}{$\begin{array}{l}\text { joules/coulomb } \\
\text { 4. } 04 \times 10^{:} \\
\text {4. } 14 \\
4.10 \\
4.10 \\
4.07 \\
3.96 \\
3.86 \\
3.82 \\
3.73 \\
3.71 \\
3.60 \\
3.64 \\
3.69 \\
3.71\end{array}$} & $\begin{array}{l}\text { Mev } \\
18.2 \\
19.8 \\
2.7 \\
25.9 \\
31.3 \\
36.7 \\
42.1\end{array}$ & $\begin{array}{l}\text { joules/coulomb } \\
4.19 \times 10^{5} \\
4.18 \\
4.17 \\
4.15 \\
4.13 \\
4.11 \\
4.14\end{array}$ \\
\hline & & \multicolumn{2}{|c|}{ Experiment 3} \\
\hline & & & \\
\hline & & $\begin{array}{l}20 \\
25 \\
30\end{array}$ & $\begin{array}{l}4.12 \times 10^{5} \\
4.08 \\
4.11\end{array}$ \\
\hline \multicolumn{2}{|c|}{ Experiment 4} & $\begin{array}{l}35 \\
40 \\
45\end{array}$ & $\begin{array}{l}4.10 \\
4.05 \\
4.02\end{array}$ \\
\hline $\begin{array}{r}6 \\
8 \\
10 \\
13 \\
16 \\
19\end{array}$ & $\begin{array}{l}\text { 4. } 10 \times 10^{5} \\
4.17 \\
3.99 \\
4.07 \\
4.09 \\
4.17\end{array}$ & $\begin{array}{r}50 \\
60 \\
70 \\
90 \\
110 \\
130 \\
150 \\
170\end{array}$ & $\begin{array}{l}3.99 \\
3.94 \\
3.86 \\
3.80 \\
3.84 \\
3.81 \\
3.82 \\
3.87\end{array}$ \\
\hline
\end{tabular}

the other two curves is explained in the following section). Above $20 \mathrm{Mev}$, its shape was obtained from a weighted a verage of ealorimeter and crystal points, where the weights were inversely proportional to the quoted errors. Below $20 \mathrm{Mev}$, the shape of the eurve was influenced by the results of additional experimental calibrations made with $\gamma$-rays and $\mathrm{X}$-rays of energy less than $1.5 \mathrm{Mev}$. These extra ealibrations were made to help determine the sensitivity of $\mathrm{P} 2-4$ to monoenergetie photons, as described in the following seetion.

The $34.5-\mathrm{Mev}$ calibration plotted in figure 7 is based on ealorimeter measurements made at the Max Planek Institut für Biophysik in Frankfurt [8]. They were made to ealibrate P2-6, a repliea chamber belonging to this institute, and were transferred to P2-4 by direet comparison of the two ehambers, as described in section 6 . The plotted point has been corrected to a beam diameter of $4.2 \mathrm{em}$ and a filtration of $4.5 \mathrm{~g} / \mathrm{em}^{2}$ of aluminum.

The $146-\mathrm{Mev}$ calibration is based on ealorimeter measurements made at the University of Illinois 
[9]. 'They were transferred to P2-4 by constructing a replica of the Illinois chamber and comparing it with $\mathrm{P} 2-4$ at the NBS. No corrections have been made for differences in beam filtration and diameter, but these corrections should be very small.

The P2-4 calibration was also determined at low energies, in experiments using radioactive sources and a $250-\mathrm{kv}$ constant potential X-ray tube, and the results are listed in tables 4 and 5 .

TABLE 4. Absolute calibration of chamber P2-4 in a 4.2$\mathrm{cm}$-diam $\gamma$-ray beam at $20^{\circ} \mathrm{C}$ and $760 \mathrm{~mm}$ of mercury

\begin{tabular}{c|c|c}
\hline Source & Photon energy & Cal $(P 2-4)$ \\
& \multicolumn{1}{c}{ Mev } & joules/coulomb \\
Cs137 & 0.66 & $4.59 \times 10^{5}$ \\
$C^{80}$ & 1.25 & 4.14 \\
\hline
\end{tabular}

TABLE 5. Absolute calibration of $\mathrm{P}^{2}-4$ in a $4.2-c m-d i a m$ low-energy $\mathrm{X}$-ray beam at $20^{\circ} \mathrm{C}$ and $760 \mathrm{~mm}$ of mercury

\begin{tabular}{|c|c|c|c|c|c|}
\hline \multirow{2}{*}{$E_{\max }$} & \multicolumn{4}{|c|}{ Filter thickness } & \multirow{2}{*}{$\mathrm{Cal}\left(P_{2-4}\right)$} \\
\hline & $A l$ & $\mathrm{~Pb}$ & Sn & $\mathrm{Cu}$ & \\
\hline $\begin{array}{r}\text { Yev } \\
0.050 \\
.100 \\
.150 \\
.200 \\
.250 \\
.250\end{array}$ & $\begin{array}{l}m m \\
3 \\
3 \\
3 \\
3 \\
3 \\
6.18\end{array}$ & \begin{tabular}{l}
$m m$ \\
0.125 \\
.53 \\
\hdashline 0.7 \\
2.7 \\
2.7
\end{tabular} & \begin{tabular}{l}
$m m$ \\
\hdashline 1.54 \\
4.0 \\
1.0 \\
1.0
\end{tabular} & \begin{tabular}{r}
$m m$ \\
\hdashline 4.15 \\
0.61 \\
$\quad .59$ \\
11.85
\end{tabular} & 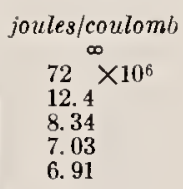 \\
\hline
\end{tabular}

In each case, the photon-beam intensity was obtained from measurements of the exposure dose in roentgens/min, and the calibration was taken to be the product of intensity (watts $/ \mathrm{cm}^{2}$ ) and beam cross section $\left(\mathrm{cm}^{2}\right)$, divided by the ionization current (amperes). The beam was $6.4 \mathrm{~cm}$ in diameter in each experiment, but small corrections have been applied to the calibrations listed in tables 4 and 5 so that they refer to a $4.2-\mathrm{cm}$ beam.

In the experiments with radioactive sources, measurements of rocntgens/min were made with a carbon cavity chamber [10], and the beam intensities were calculated using the conversion factors of 2,959 ergs $/ \mathrm{cm}^{2} /$ roentgen for $\mathrm{Cs}^{137}$ [11] and

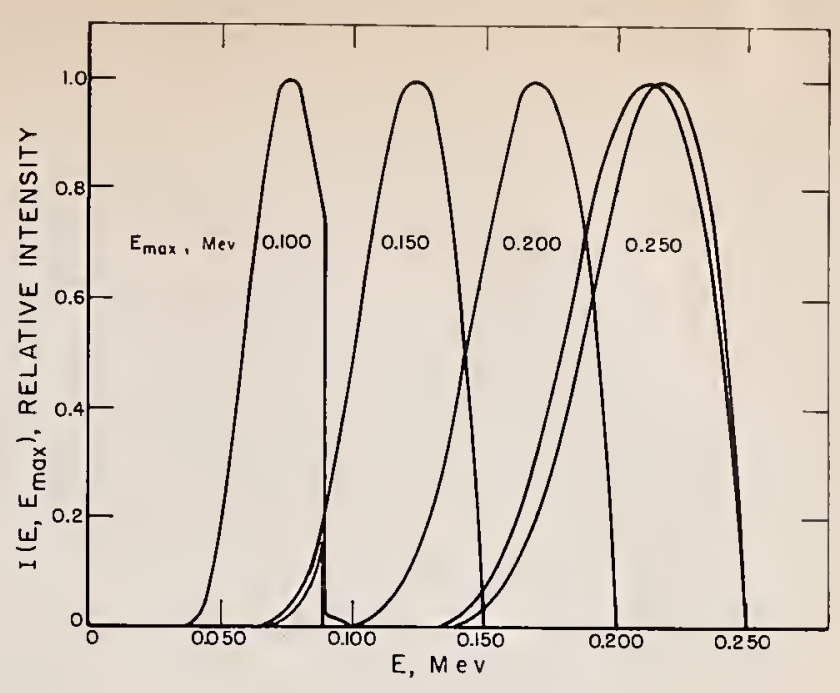

Figure 8. Relative spcctral-intensity distributions for filtercd $\mathrm{X}$-ray beams obtaincd from a 250-Kv constantpotential $\mathrm{X}$-ray tube.

The small peak between $0.07 \mathrm{Mev}$ and the $K$ absorption edge of lead at 0.088 Mev belongs to the lightly filtered $0.250-$ Mev spectrum

$3,391 \mathrm{ergs} / \mathrm{cm}^{2} /$ roentgen for $\mathrm{Co}^{60}[12]$. In the X-ray tube experiments, measurements of roentgens/min were made with a free-air ionization chamber [13], and the beam intensities were calculated from the equation

$$
\frac{\text { watts } / \mathrm{cm}^{2}}{\operatorname{rocntgen} / \mathrm{min}}=\frac{1}{6} \times 10^{-8} \frac{\int_{0}^{E_{\max }} I\left(E, E_{\max }\right) d E}{\int_{0}^{E_{\max }} \frac{I\left(E, E_{\max }\right) d E}{R(E)}}
$$

where $I\left(E, E_{\max }\right)$ is the differential intensity spectrum in units proportional to watts $/ \mathrm{cm}^{2} / \mathrm{Mev}$, and $R(E)$ is the conversion factor $\mathrm{ergs} / \mathrm{cm}^{2} /$ roentgen for photons of energy $E . \quad I\left(E, E_{\max }\right)$ was calculated by assuming that at these low energies, the unfiltered intensity spectra are proportional to $\left(E_{\max }-E\right)$ [1], and correcting for filtration with published total attenuation coefficients [14]. The filtered spectra are shown in figure $8 . R(E)$ was taken from the literature [15].

\section{Sensitivity of P2-4 to Monoenergetic Photons}

The calibration of an ionization chamber can be calculated from the equation

$$
\mathrm{Cal}=\frac{\int_{0}^{E_{\max }} I\left(E, E_{\max }\right) d E}{\int_{0}^{E_{\max }} S(E) I\left(E, E_{\max }\right) d E}
$$

where $I\left(E, E_{\max }\right)$ is the differential intensity spectrum at the face of the chamber, and $S(\dot{E})$ is the chamber sensitivity for photons of energy
$E$, the ionization charge produced by unit incidentradiation energy. Knowledge of the sensitivity is a prerequisite for ealculation of the manner in which the calibration depends on the $\mathrm{X}$-ray spectrum.

The sensitivity of $\mathrm{P} 2-4$ to monoenergetic photons is plotted as a function of photon energy in figure 9. 'The solid curve was obtained by solving eq (5) for $S(E)$, using the calibrations described in the previous section. With the data of table $5, I\left(E, E_{\max }\right)$ was taken from figure 8. In this case the solution was obtained by assigning 


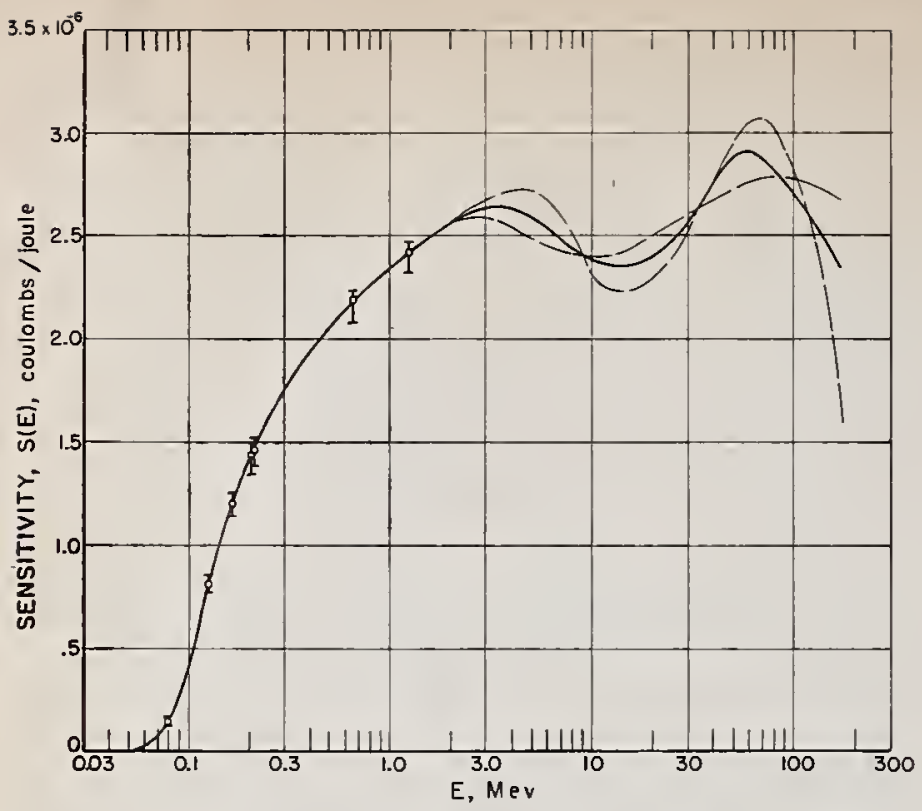

FIGURE 9. Sensitivity of $\mathrm{P}^{2}-4$ to a $4.2-\mathrm{cm}$-diam beam of monoenergetic photons, at $20^{\circ} \mathrm{C}$ and $\gamma 60 \mathrm{~mm}$ of mercury.

The solid curre is a best fit to the experimental data, and the dashed curves postulated extremes in the shape of the curve.

an average photon energy to each of these spectra, plotting $1 / \mathrm{Cal}(\mathrm{P} 2-4)$ at this energy, in figure 9 , drawing a smooth curve through these points, and calculating Cal (P2-4) from eq (5). The discrepancy between calculated and measured calibrations was removed by adjustment of the average energies.

The values of $S(E)$ plotted at 0.66 and 1.25 Mer in figure 9 are simply the inverse of the calibrations listed in table 4 for $\mathrm{Cs}^{137}$ and $\mathrm{Co}^{60}$, respectively, since the spectra are approximately delta functions. At higher energies, eq (5) was solved for $S(E)$ by the inverse-matrix technique described in reference [16]. In this case, the calibrations came from the solid curve in figure 7 , and $I\left(E, E_{\mathrm{max}}\right)$ was taken from tabulations of Schiff integrated-over-angles differential-intensity spectra [17], corrected for a filtration of 4.5 $\mathrm{g} / \mathrm{cm}^{2}$ of aluminum [18]. Examples of the predicted spectra are shown in figure 10. This high-energy solution for $S(E)$ reproduces the solid-calibration curve of figure 7 to a few tenths of 1 percent.

The estimated uncertainties in the sensitivity curve are indicated by vertical lines at low photon energies. The radioactive source errors include uncertainties of +3 percent, -1 percent in the determination of roentgens/min, ${ }^{8}$ and errors in the conversion to intensity units of \pm 1.5 percent for $\mathrm{Cs}^{137}$ and \pm 1.2 percent for $\mathrm{Co}^{60}$. The $\mathrm{X}$-ray tube errors include \pm 1 percent for the roentgens/ min determinations, \pm 3 percent for the conversion to intensity units, and \pm 1 percent for uncertainty in the average energies. The plotted errors are the sums of these individual errors.

${ }^{8}$ This asymmetry arises from the presence of scattered radiation, which is not completely understood at present but is under study.

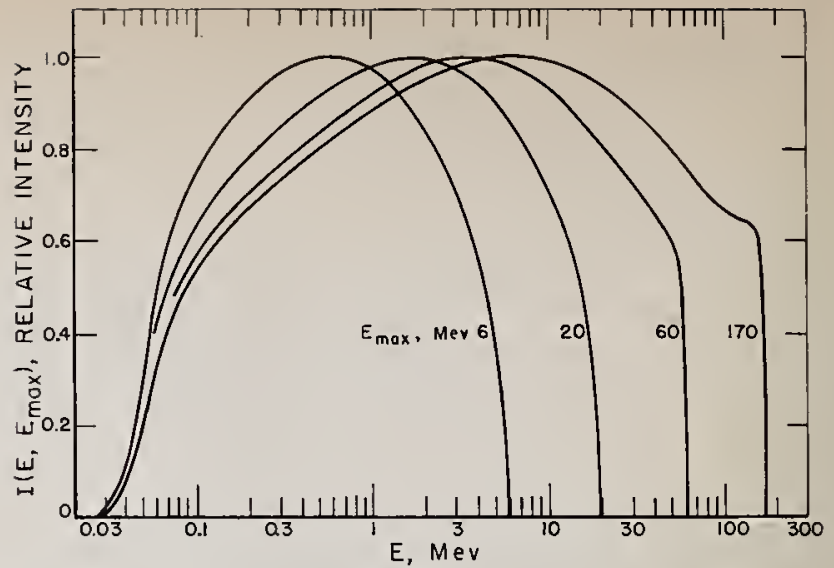

FIgURE 10. Relative spectral-intensity distributions for bremsstrahlung beams filtered by $4.5 \mathrm{~g} / \mathrm{cm}^{2}$ of aluminum.

The estimated errors in $S(E)$ above $2 \mathrm{Mev}$ were obtained by making the trial distortions of the calibration curve shown by dashed lines in figure 7 . These curves lie within \pm 2 percent of the solid best-fit curve, but include changes in curvature which affect the sensitivity curve more drastically than a simple change in absolute magnitude does. They change the predicted sensitivity curve as shown by the dashed lines in figure 9 . It is possible to predict values of $S(E)$ outside of the dashed curves by postulating additional oscillations of the calibration curve. but this would be difficult to justify because all of the physical interactions which determine the calibration vary slowly with energy. This analysis of the uncertainty in $S(E)$ shows that the precise shape of the sensitivity curve is not very well known at high energies, but the presence of two maximums appears to be well established, and this can be qualitatively explained with the following arguments.

At low photon energies, the shape of $S(E)$ is determined by the photon-attenuation coefficients in Dural, which decrease rapidly with increasing $E$, so that an increasing fraction of the incident energy penetrates the thick front wall of the chamber. In the neighborhood of a few Mev, the product of attenuation coefficient and wall thickness is of the order of unity, and the exponential absorption is less sensitive to changes in energy. In this region, the predominant effect is a decrease in the efficiency of converting photon energy into electron energy, giving rise to the lowenergy maximum in $S(E)$.

At higher photon energies, the increasing range of the secondary electrons means that the region in the Dural where the electrons producing air ionization are generated moves toward the front of the chamber. This decreases the effective wall attenuation and increases $S(E)$. This increased electron range also means that a larger volume of Dural is contributing to air ionization, but this change does not affect the calibration because it is compensated by a decrease in the fraction of its energy which each electron deposits in the air cavity. At energies where the electron 
ranges are comparable with the front-wall thickness (40 Mev electrons), the volume of Dural contributing to the ionization no longer increases with energy, but the fraction of energy deposited by each electron continues to decrease with increasing energy. At the same time, bremsstrah- lung production increases, and an increasing fraction of the secondary electron energy is reconverted into photons and becomes unavailable for ionization production. These two effects in combination cause a drop in $S(E)$ and lead to the high-energy maximum.

\section{Variations of the P2 Calibration}

The P2-4 bremsstralilung calibration curve of figure 7 cannot be used directly for an arbitrary X-ray exposure, because the calibration depends upon the value of several cxperimental parameters, which may differ from the values used during the calibration experiments. These are

1. The temperature and pressure of the air in the chamber.

2. The thickness and atomic number of the filters in the X-ray beam.

3. The diameter and intensity distribution of the incident beam.

The variation with air temperature and pressure obeys the idcal gas laws, and the calibration may be corrected for this variation by multiplying it by the factor

$$
F_{\iota p}=2.592 \frac{(t+273.2)}{p},
$$

where $t$ and $p$ are respectively the temperature $\left({ }^{\circ} \mathrm{C}\right)$ and pressure $(\mathrm{mm}$ of mercury) of the air in the chamber during an exposure. $t$ can be read from the attached thermometer, but $p$ must be determined from a measurement made outside the chamber. This factor would also include a small humidity corrcction except for the use of drier in the chamber air inlet.

'The variation with filter thickness and atomic number must be calculated with the help of eq $(5)$, and with $I\left(E, E_{\max }\right)$, the Schiff unfiltered spectrum [17], corrected for absorption by the materials in the beam. These corrections multiply the unfiltered spectrum by an exponential of the form $e^{-\Sigma_{i} \gamma_{i}(E) t_{i}}$, where $t_{i}$ is the thickness of the $i$ th

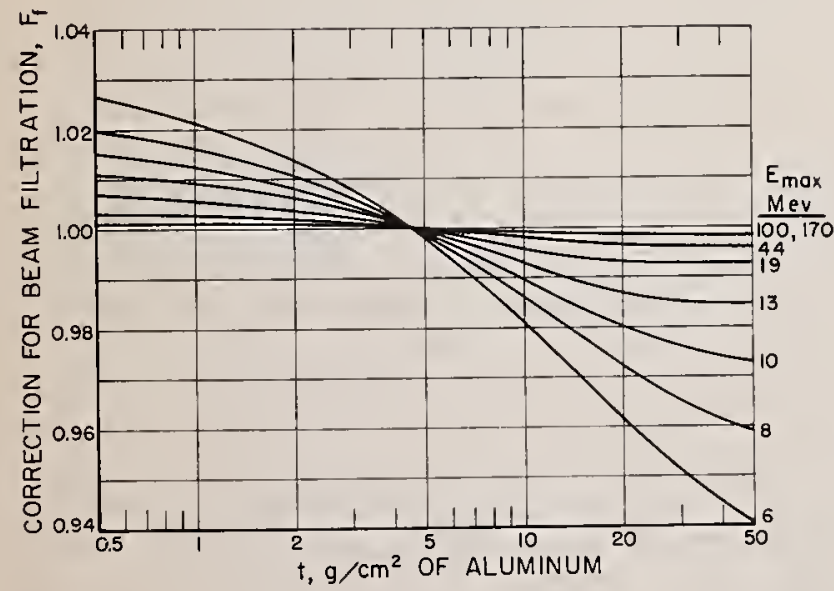

Figure 11. Ratio of $P \mathscr{Z}-4$ calibration in a beam filtered by $\mathrm{t} \mathrm{g} / \mathrm{cm}^{2}$ of aluminum to $P Q-4 c$ alibration in a beam filtered by $4.5 \mathrm{~g} / \mathrm{cm}^{2}$ of aluminum. filter and $\gamma_{i}(E)$ is its attenuation coefficient for photons of energy $E$. The values of $S(E)$ used in this calculation may be taken directly from figure 9 . 'The correction for filtration multiplies the calibration of figure 7 by a second factor:

$$
F_{f}=\frac{\operatorname{Cal}\left(t_{i}, Z_{i}\right)}{\mathrm{Cal}\left(4.5 \mathrm{~g} / \mathrm{cm}^{2} \text { of } \mathrm{Al}\right)}
$$

These calculations have been performed for the special cases of aluminum and copper filter's using total attenuation coefficients from references [14] and [18], which assume that no scattered photons from the filter reach the P2 chamber. The values of $F_{f}$ obtained are shown in figures 11 and 12 as a function of filter thickness, $t\left(\mathrm{~g} / \mathrm{cm}^{2}\right)$, for a few representative values of $E_{\max }$. The variation with energy in the aluminum curves is quite regular, but the copper curves exhibit a maximum near $100 \mathrm{Mev}$ for large $t$, related to the minimum in $S(E)$ at $14 \mathrm{Mev}$. These curves are almost independent of errors in the assumed spectra and absorption coefficients, but they do depend on the precise shape of $S(E)$. If $S(E)$ lies within the limits shown in figure 9, figures 11 and 12 are accurate to within \pm 0.2 percent for $t \leq 4.5 \mathrm{~g} / \mathrm{cm}^{2}$ of aluminum and $2 \mathrm{~g} / \mathrm{cm}^{2}$ of copper, respectively. The unccrtainties for thicker filters increase approximately linearly with $t$ and are about \pm 0.8 percent at $50 \mathrm{~g} / \mathrm{cm}^{2}$, for energies less than $50 \mathrm{Mev}$. They are smaller for high energies, and are only about \pm 0.3 percent at $170 \mathrm{Mev}$, for $t=50 \mathrm{~g} / \mathrm{cm}^{2}$.

The variation with beam diameter and intensity distribution was investigated by observing the

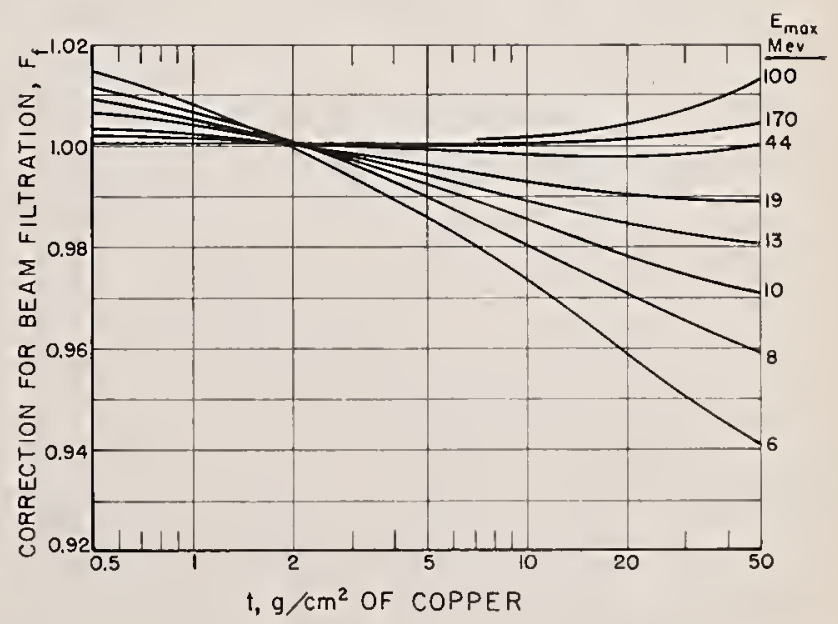

Figure 12. Ratio of $P Q-4$ calibration in a beam fillered by $t$ a/cm $\mathrm{cm}^{2}$ of copper to $P 2-4$ calibration in a beam fillered by $4.5 \mathrm{~g} / \mathrm{cm}^{2}$ of aluminum. 


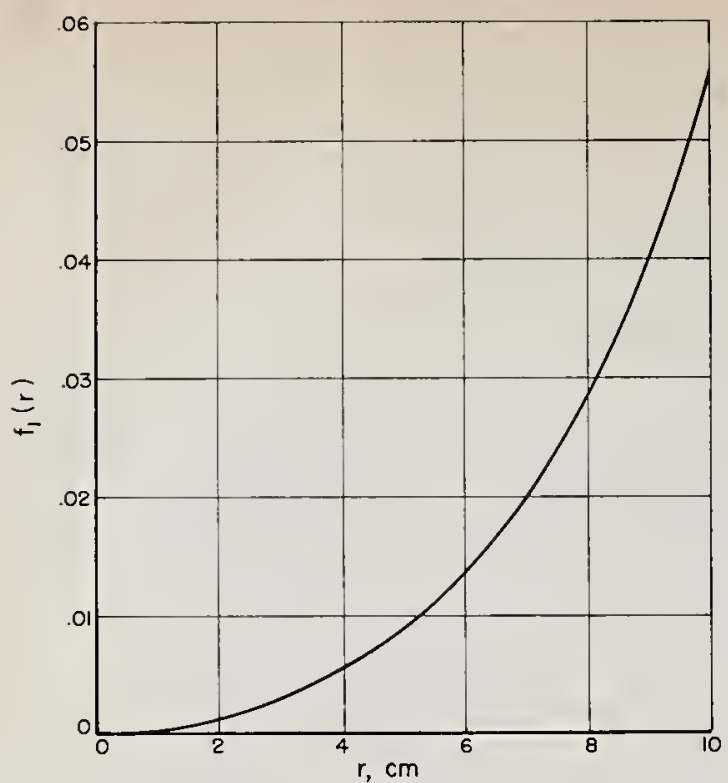

Figure 13. Relative dependence of $P \mathbb{Q}-4$ calibration on radius of beam incidence.

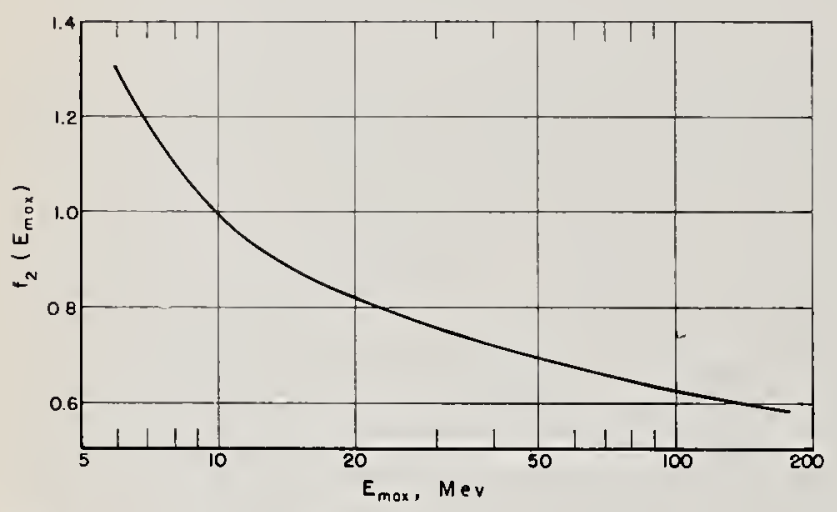

Figure 14. Energy-dependent multiplier used to calculate dependence of $\mathrm{P}^{2}-4$ calibration on radius of beam incidence.

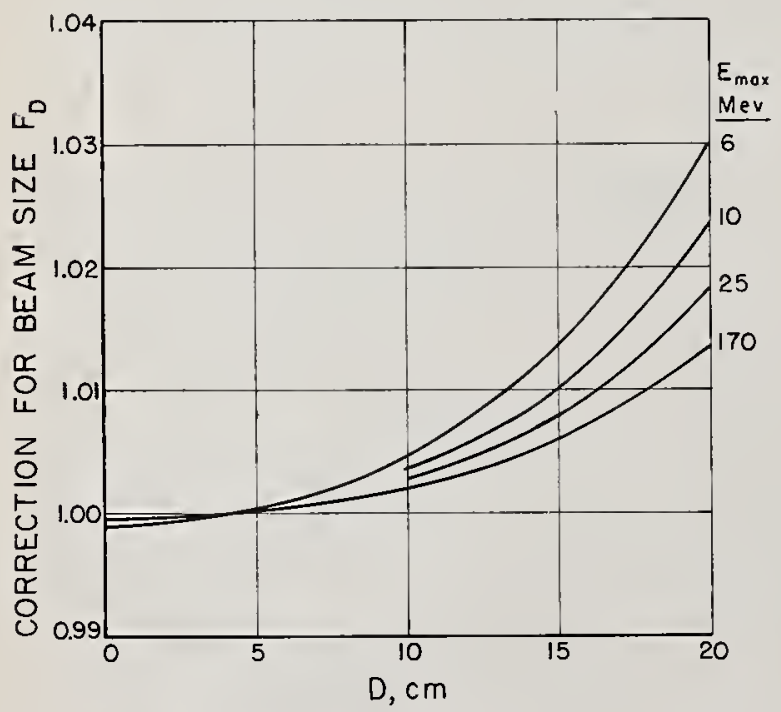

Figure 15. Ratio of $P_{2} 2-4$ calibration in an $X$-ray beam of diameter $\mathrm{D}$ to that in a 4.2-cm-diam beam, for beams of uniform intensity. change in response when a P2 chamber was bombarded at different radii by $1.5-\mathrm{cm}$-diam beams of various $E_{\mathrm{max}}$, and of unit total energy. This change depended on the $E_{\max }$ used, but it was found that the dependence on radius, $r(\mathrm{~cm})$, could be separated from the dependence on $E_{\mathrm{max}}$, and the relative response could bc cxpressed as

$$
R\left(r, E_{\max }\right)=1-f_{1}(r) f_{2}\left(E_{\max }\right) .
$$

The functions $f_{1}(r)$ and $f_{2}\left(E_{\max }\right)$ are plotted in figures 13 and 14, respectively. The latter has been arbitrarily normalized to unity near $10 \mathrm{Mev}$.

The beam-sizc correction inultiplies the calibration of figure 7 by the factor

$F_{D}=\frac{\int_{0}^{2 . I \mathrm{cma}} r I\left(r, E_{\mathrm{max}}\right) R\left(r, E_{\mathrm{max}}\right) d r \int_{0}^{\frac{D}{2}} r I\left(r, E_{\mathrm{max}}\right) d r}{\int_{0}^{\frac{D}{2}} r I\left(r, E_{\mathrm{max}}\right) R\left(r, E_{\mathrm{max}}\right) d r \int_{0}^{2.1 \mathrm{~cm}} r I\left(r, E_{\mathrm{max}}\right) d r}$

where $R\left(r, E_{\max }\right)$ comes from eq $(8)$ and $I\left(r, E_{\max }\right)$ is the relative intensity of the incident beam at radius $r$. These calculations have been performed for the ideal case where the beam intensity is uniform (for $r<\frac{D}{2}$ ), and the results arc shown 9 as a function of $D$ in figure 15 for several values of $E_{\max }$.

The corrections for beam filtration and diameter for the calibration experiments came directly from figures 11 and 15, respectively. The beam intensity was not uniform in these experiments, but the corrections for beam dianeter were almost negligible, and are quite insensitive to the precise shape of $I\left(r, E_{\mathrm{max}}\right)$.

The three factors of eqs (6), (7), and (9) arc enough to correct the P2-4 calibration for use in most experimental situations, but a fourth factor is required if a different $\mathrm{P} 2$ chamber is used. This is

$$
F_{c}=\frac{\text { Cal (replica chamber })}{\text { Cal }(\mathrm{P} 2-4)}
$$

a factor which is most reliably determined by direct experimental comparison of the replica chamber with either $\mathrm{P} 2-4$ itself or another chamber which has been compared with P2-4. The comparisons are made with the experimental arrangement of figure 4 , measuring the $\mathrm{P} 2$ ionization charge collected per unit monitor response for each of the chambers in turn. At the present time there are eleven $\mathrm{P} 2$ chambers which have been experimentally intercompared.

The first four, $\mathrm{P} 2-1$ to $\mathrm{P} 2-4$, belong to the National Burcau of Standards, and the measured

7 These curves are based on measurements with a beam filtered by 4.5 $\mathrm{g} / \mathrm{cm}^{2}$ of aluminum and may change slightly if the filtration is changed. 
values of $F_{c}$ for these chambers are listed in table 6 for several maximum photon energies between 6 and $170 \mathrm{Mev}$. The remaining seven chambers belong in various institutes around the world. Their locations are shown in table 7 , along with the measured values of $F_{c}$ and the energies at which these measurements were made [19]. Their labels, P2-n, correspond to the order in which they were calibrated.

TABlE 6. Measured calibration ratios, $\mathrm{F}_{\mathrm{c}}$, of NBS P2 chambers

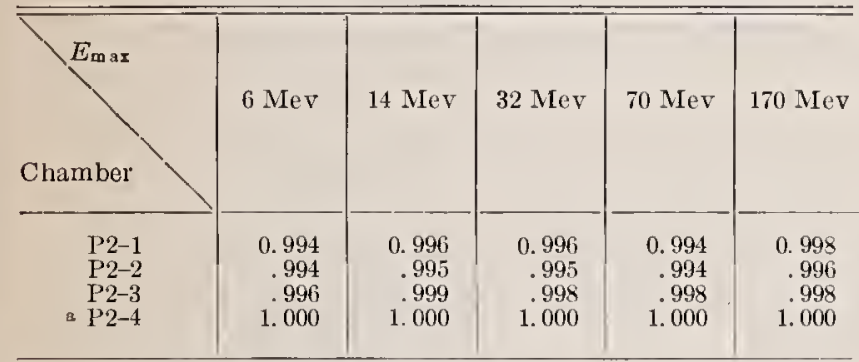

a Equal to unity by definition of $F_{\mathrm{e}}$.

TABLE 7. Measured calibration ratios of other P2 chambers

\begin{tabular}{|c|c|c|c|}
\hline Chamber & Institute & $E_{\mathrm{max}}$ & $F_{c}$ \\
\hline P2-5 & $\begin{array}{l}\text { Institut National d'IIygiene, Paris, } \\
\text { France. }\end{array}$ & $\begin{array}{r}\text { Mev } \\
18 \\
22\end{array}$ & $\begin{array}{r}0.994 \\
.994\end{array}$ \\
\hline P2-6 & $\begin{array}{l}\text { Max Planek Institut für Bioplyysik, } \\
\text { Frankfurt-am-Main, Grermany. }\end{array}$ & $\begin{array}{l}20 \\
34.5\end{array}$ & $\begin{array}{l}\text { 1. } 001 \\
0.999\end{array}$ \\
\hline$P 2-7$ & $\begin{array}{l}\text { Kantonsspital Zürieh, Zürich,Switzer- } \\
\text { land. }\end{array}$ & 31 & 991 \\
\hline $\mathrm{P} 2-8$ & $\begin{array}{l}\text { Inštitut Jožef Stefan, Ljubljana, } \\
\text { Yugoslavia. }\end{array}$ & 18 to 30 & 1. 028 \\
\hline $\begin{array}{l}\mathrm{P} 2-9 \\
\mathrm{P}^{\prime 2}-10\end{array}$ & Tohoku University, Sendai, Japan. & $\begin{array}{l}32 \\
32\end{array}$ & $\begin{array}{l}\text { 1. } 000 \\
\text { 1. } 001\end{array}$ \\
\hline$P 2-11$ & $\begin{array}{l}\text { University of Illinois, Urbana, lllinois, } \\
\text { U.S.A. }\end{array}$ & 38 & 1.008 \\
\hline
\end{tabular}

The calibrations of these chamber's differ for several reasons. The calibration is a function of $X\left(\mathrm{~g} / \mathrm{cm}^{2}\right)$, the mass thickness of the front wall, $T(\mathrm{~cm})$, the total thickness of the air cavity in the ion collection assembly, and $Z$, the atomic number of the front-wall alloy. It is a simple matter to predict the variation with $X$ and $T$. For chambers made of the same alloy, where $X$ and $T$ are only slightly different from the $X$ and $T$ for P2-4, the change in calibration is a linear function of these differences:

$$
F_{c}=1+a\left(X_{i}-X_{4}\right)-b\left(T_{i}-T_{4}\right),
$$

where subscript $i$ refers to the dimensions of channber P2-i. The coefficient $a$ has been deternined at several values of $E_{\text {max }}$ between 6 and $170 \mathrm{Mev}$ by measuring the change in the response of P2-4 when $X$ is changed, and is plotted in figure 16 . The coefficient $b=0.20 \mathrm{~cm}^{-1}$, the inverse of the nominal value of $T$.

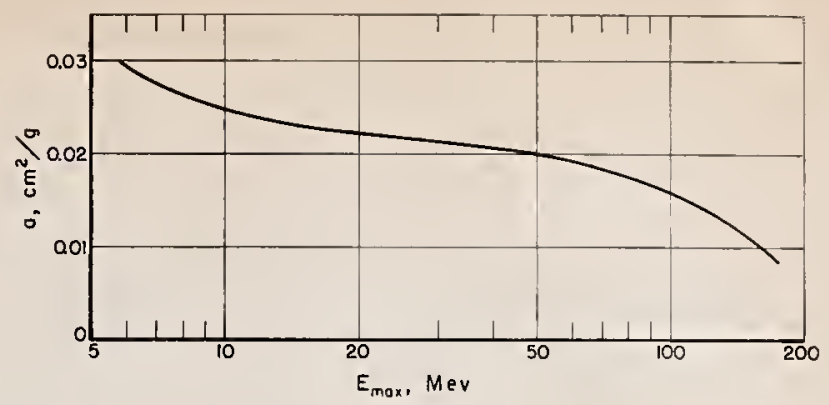

FiguRE 16. Fractional decrease in P2-4 calibration per $\mathrm{g} / \mathrm{cm}^{2}$ increase in front-wall thickness.

In using eq (11), it is convenient to define $X$ and $T$ in terms of thicknesses and densities of the individual chamber components :

$$
\begin{gathered}
X=X(1)+X(4)+X(10)+5.5 X(11) \\
X(j)=\rho(j) t(j) \\
T=6[\overline{T(14)-\bar{T}(11)]}
\end{gathered}
$$

where the numbers in parentheses refer to the corresponding pieces in the chamber plans. $\rho(j)$ and $t(j)$ are respectively the density $\left(\mathrm{g} / \mathrm{cm}^{3}\right)$ and thickness $(\mathrm{cm})$ of piece No. $j^{10} \quad$ Note that eq (12) includes half the total thickness of the eleven inner plates, so that the front-wall thickness is nicasured to the center of the ion-collection asscmbly. The quantities $\bar{T}(14)$ and $\bar{T}(11)$ in eq (13) are, respectively, the average thickncsses of the spacers in the high-voltage stack of plates and of the inner plates in the collector stack.

The values of $X$ and $T$ are known for several of the chambers which have been intercompared, and these are listed in table 8, along with the values of $F_{c}$ calculated from eq (11). 'The alloy densitics listed indicate that the alloy compositions of these chambers are approximately the same. It can be seen from this table that the preclicted $F_{c}$ 's agree with the measured values to within a few tenths of one percent, which is within the uncertainties inherent in the measurements of $F_{c}$,

\begin{tabular}{|c|c|c|c|c|c|c|}
\hline \multirow{2}{*}{ Chamber } & \multirow{2}{*}{$E_{\mathrm{max}}$} & \multirow{2}{*}{$X$} & \multirow{2}{*}{$T$} & \multicolumn{2}{|c|}{$F_{\mathrm{e}}$} & \multirow{2}{*}{$\rho$} \\
\hline & & & & Calculated & Measured & \\
\hline $\begin{array}{l}\mathrm{P} 2-1 \\
\mathrm{P}^{\prime} 2-2 \\
\mathrm{P}^{2} 2-3 \\
\mathrm{P}^{2} 2-4 \\
\mathrm{P}^{\prime} 2-5 \\
\Gamma^{\prime} 2-9 \\
I^{\prime} 2-10\end{array}$ & $\begin{array}{c}\text { Mev } \\
32 \\
32 \\
32 \\
32 \\
22 \\
32 \\
32\end{array}$ & $\begin{array}{l}g / c n^{2} \\
27.30 \\
27.30 \\
27.43 \\
27.41 \\
27.25 \\
27.38 \\
27.39\end{array}$ & $\begin{array}{c}\mathrm{cm} \\
5.061 \\
5.063 \\
5.069 \\
5.062 \\
5.073 \\
5.060 \\
5.052\end{array}$ & $\begin{array}{r}0.998 \\
.997 \\
.999 \\
1.000 \\
0.995 \\
.999 \\
1.000\end{array}$ & $\begin{array}{r}0.996 \\
.995 \\
.995 \\
1.000 \\
0.994 \\
1.000 \\
1.001\end{array}$ & $\begin{array}{l}\mathrm{g} / \mathrm{cm}^{3} \\
\text { 2. } 786 \\
\text { 2. } 780 \\
2.790 \\
2.790 \\
2.757 \\
2.793 \\
2.794\end{array}$ \\
\hline
\end{tabular}
$X$, and $T$.

TABLE 8. Physical parameters and calibration ratios of scveral P2 chambers

If $t(1), t(4)$, and $l(10)$ shoutd be measured near the centers of the corresponding pices , since their farens are seldoun flat. 
The abnormally large $F_{c}$ for $\mathrm{P} 2-8$ (table 7 ) is caused by changed dimensions, since the inner plates used in this chamber are $1 \mathrm{~mm}$ thick instead of $0.8 \mathrm{~mm}$, as specified in the chamber plans. This change should reduce $T$ by $0.12 \mathrm{~cm}$ and increase $\mathrm{X}$ by $0.3 \mathrm{~g} / \mathrm{cm}^{2}$, which would be expected to increase the calibration by about 3 percent, in reasonable agreement with the measured increase.

The dependence of the calibrations on $Z$ is mole difficult to analyze quantitatively, since the physical interactions which determine the calibration depend upon $Z$ in different ways. Per atom, the probability of a Compton interaction varies as $Z$, that for pair production varies as $Z^{2}$, and the electron stopping power varies as $Z$. As an alternative approach, this effect has been investigated at several energies by replacing the removable plates of $\mathrm{P} 2-4$ (piece No. 4) by plates made of two different alloys, 1100 Dural $(99 \%$ pure aluminum; $\rho=2.713 \mathrm{~g} / \mathrm{cm}^{3}$ ) and 7178 Dural (2.0\% copper, $2.7 \%$ magnesium, $6.8 \%$ zinc, $0.3 \%$ chromium; $\rho=2.827 \mathrm{~g} / \mathrm{cm}^{3}$ ), and observing the change in calibration. The plates werc machined to have the same mass thickness as the plates they replaced $\left(19.82 \mathrm{~g} / \mathrm{cm}^{2}\right)$ to eliminate the effects of changes in $X$. The measured changes are listed in table 9. 'They indicate that an increase in the alloy purity will decrease the chamber calibration bclow about $100 \mathrm{Mev}$ and will increase it at higher energies. It must be remembered that pieces Nos. 1, 10, and 11 were not changed in these tests, so that the effect of using either of these alloys throughout the chamber will be even larger. If each of the numbers in table 9 is expressed as $1+\epsilon$, the proper number to be used for chambers constructed completely of these alloys should be about $1+1.4 \epsilon$, where 1.4 is the ratio $[X(1)+X$ $(4)+X(10)] / X(4)$.

It is tcmpting to use the alloy density, $\rho$, which can be relatively casily measured, as a rough measure of $Z$. There is no exact proportionality between these quantities, but addition of heavy metals usually increases both $\rho$ and $Z$. Then an cmpirical term like

$$
c\left(\rho_{i}-\rho_{4}\right)^{k}
$$

could be added to eq (11) in an attempt to account for changed alloy composition. The $32-\mathrm{Mev}$ data in table 9 indicates that $c=0.13$ and $k=0.95$, at least at this energy. This term would subtract 0.001 from the calculated $F_{c}$ listed for P2-1, P2-2, and $\mathrm{P} 2-5$ in table 8 and add 0.001 to the calculated $F_{c}$ for $\mathrm{P} 2-9$ and $\mathrm{P} 2-10$. These changes improve the agreement between the calculated and measured $F_{c}$ in each case, but the improvement is fortuitous. It is felt that this empirical correction term should only be used as a rough indication of
TABLE 9. Effect of changing the alloy composition of the PQ-4 front wall

\begin{tabular}{c|c|c}
\hline$E_{\mathrm{max}}$ & $\frac{\text { Cal (1100) }}{\text { Cal (2024) }}$ & $\frac{\text { Cal (7178) }}{\text { Cal (2024) }}$ \\
\cline { 1 - 2 } Mev & & \\
6 & 1.000 & \\
11 & 0.998 & \\
18 & .995 & \\
32 & .992 & 1.004 \\
70 & .996 & \\
90 & .995 & \\
120 & 1.002 & \\
150 & 1.002 & \\
170 & 1.006 & \\
\hline
\end{tabular}

the cliange resulting from use of a different alloy, and should be treated skeptically if it is larger than about 0.002 . The safest way to predict $F_{c}$ is to use an alloy with approximately the same composition and density as 2024 Dural, so that this term is negligible.

In summary of the information presented in this section, the calibration of an arbitrary P2 chamber is related to the $\mathrm{P} 2-4$ calibration by

$$
\text { Cal }(\text { replica })=F_{t p} F_{f} F_{D} F_{c} \times \text { Cal }(\mathrm{P} 2-4) \text {. }
$$

The factors $F_{t p}, F_{f}$, and $\mathrm{F}_{D}$ correct for changes in experimental conditions and can be calculated from eq (6), (7), and (9), respectively. $F_{c}$ comes from eq (10) and should be measured experimentally, but can be predicted with reasonable accuracy from eq (11) if the composition of the aluminum alloy is close to that of $\mathrm{P} 2-4$.

The authors thank the nuclear physicists of the NBS High Energy Radiation Section for their appreciation of thic valuc of an absolutely calibrated ionization-chamber beam monitor, and for their consequent interest and help in this project. Particular thanks are extended to E. G. Fuller, E. Hayward, J. E. Leiss, and R. A. Schrack for permission to present the results of their scintillation spectrometer experiments, to R. A. Schrack for his help with the filtration computations, and to H. W. Koch and J. E. Leiss for then help in the preparation of this manuscript.

We also thank S. W. Smith for providing the facilities for the low-encrgy sensitivity measurements, and H. O. Wyckoff for his help with their interpretation and for his help in arranging the replica chamber comparisons. These latter were performed with the cooperation of A. Allisy and M. 'Tubiana of Paris, M. Pohlit of Frankfurt, G. Joyet of Zurich, C. Zupančič of Ljubljana, M. Kimura of Sendai, and N. Goldwasser, R. Carrigan, and W. Swanson of Urbana, and we are grateful for their interest which made these comparisons possible. 

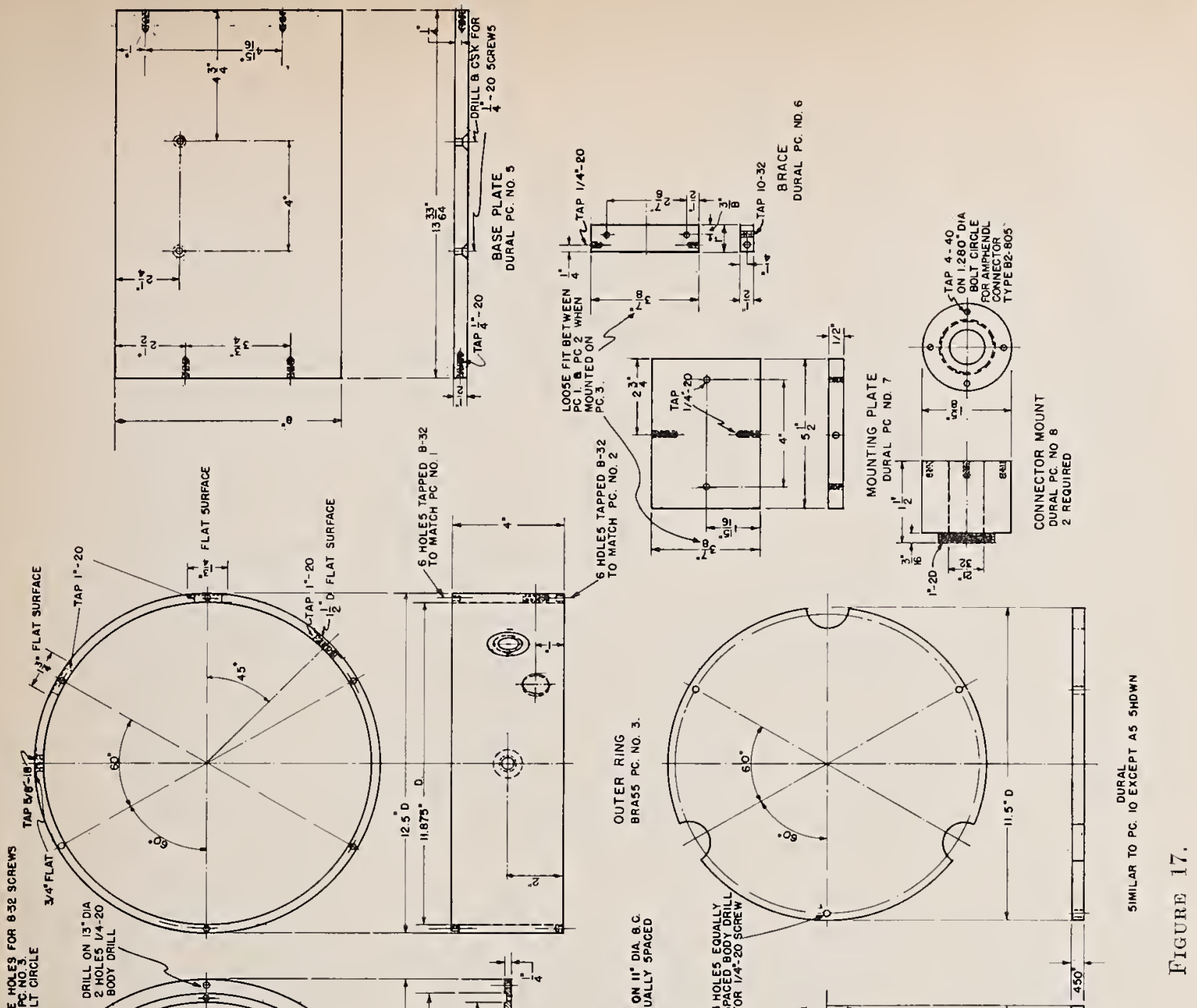


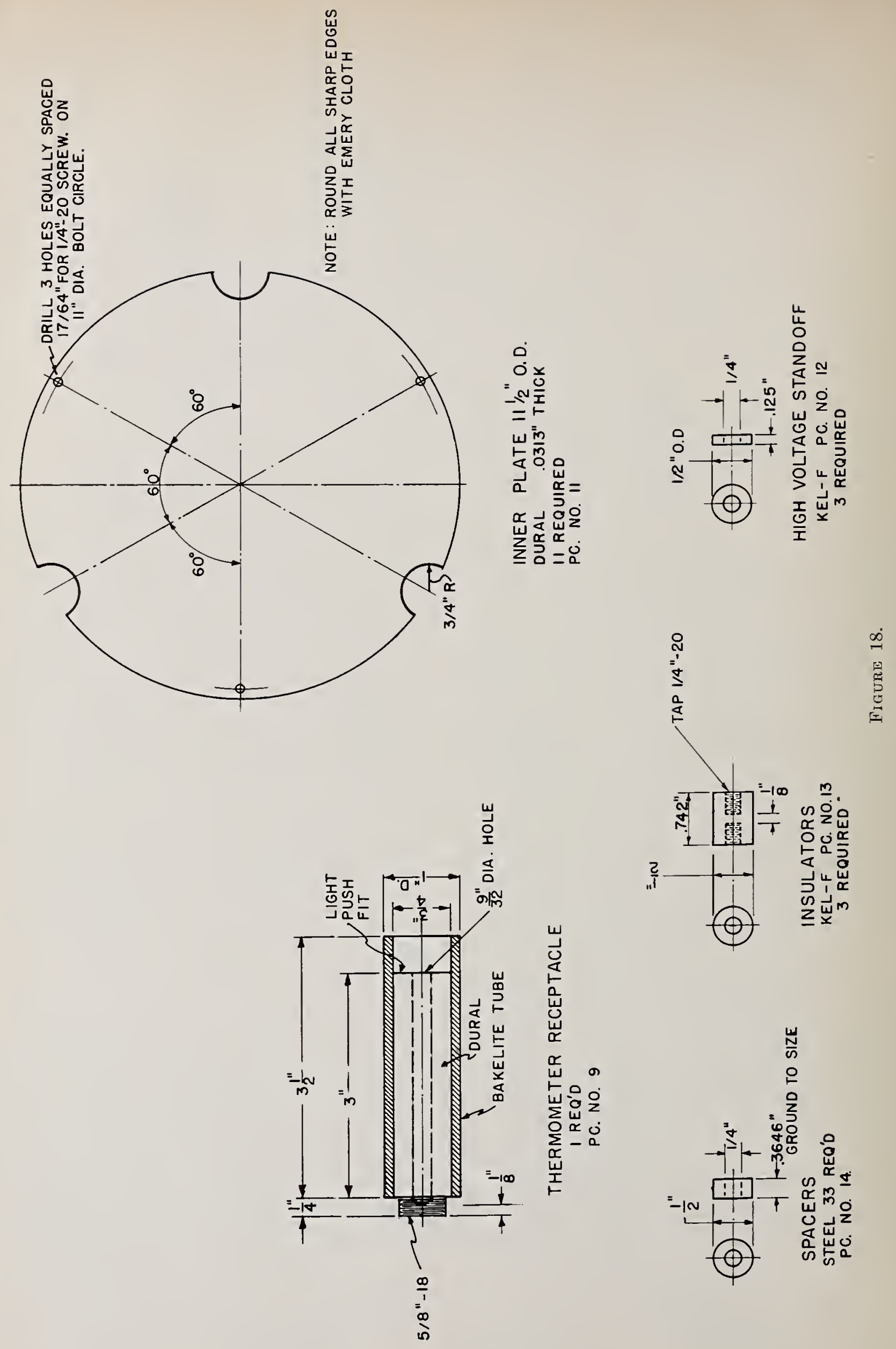



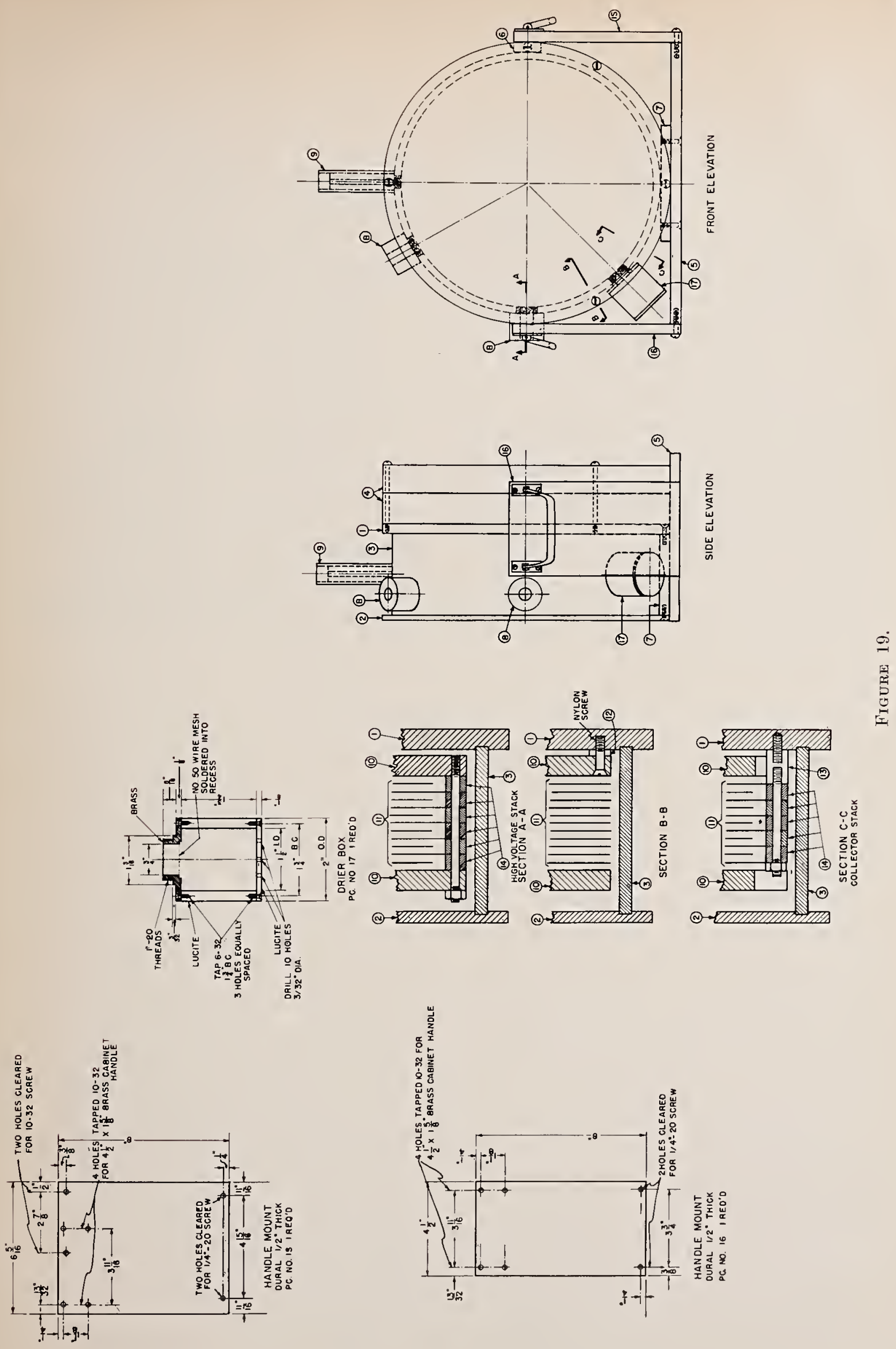


\section{References}

[1] H. W. Koch and J. W. Motz, Bremsstrahlung crosssection formulas and related data, Rev. Mod. Phys. 31, 920 (1959).

[2] A comprehensive list of references to techniques described prior to 1954 may be found in Appendix B of NBS Handb. 55, Protection against betatronsynchrotron radiations up to 100 million electron volts $(1954)$.

[3] J. S. Pruitt and S. R. Domen, Calorimetric X-ray monitor calibration at betatron energies, Radiation Research 9, (1958) A; and E. G. Fuller and E. Haward, Calibration of a monitor for use in bremsstrahlung beams, J. Research NBS $65 \boldsymbol{A}$ (Phys. and Chem.) No. 5, 401 (1961). A deseription of the two calorimeter experiments will be published in 1962 .

[4] J. S. Laughlin and J. W. Bcattie, Calorimetric determination of the energy flux of 22.5 Mev I-rays, Rev. Sci. Instr. 22, 572 (1951).

[5] H. W. Koch, J. E. Leiss, and J. S. Pruitt, Crystal spectrometer calibration of a high energy I-ray intensity monitor, Bull. APS II, 1, 199 (1956) A.

[6] R. R. Wilson, Precision quantameter for high energy X-rays, Nuclear Instr. 1, 101 (1957).

[7] See G. J. Hine and G. L. Brownell, Radiation Dosimetry (Academic Press, Inc., New York, N.Y., 1956) p. 172 for a treatment of ion recombination.

[8] J. S. Pruitt and W. Polnlit, Z. Naturforschung 15b, 617 (1960).

[9] P. D. Edwards and D. W. Kerst, Rev. Sci. Instr. 24, 490 (1953).
[10] F. H. Attix and V. H. Ritz, A determination of the gamma-ray emission of radium, J. Research NBS 59, 293 (1957).

[11] P. W. Goodwin, Calorimetric measurements on a $\mathrm{Cs}^{137}$ teletherapy unit, Radiation Research 10,6 (1959).

[12] I. T. Myers, W. H. LeBlane, and D. M. Fleming, unpublished data.

[13] NBS Handb. 64, Design of free-air ionization chambers (1957).

[14] G. W. Grodstein, X-ray attenuation coefficients from $10 \mathrm{kev}$ to $100 \mathrm{Mev}$, NBS Circ. 583 (1957)

[15] Reference [7], p. 88. The listed values of $R(E)$ were increased by $33.6 / 32.5$ on the basis of a more recent assessment of $\mathrm{IT}$ by W. Bay, W. B. Mann, H. H. Seliger, and II. O. Wyckoff, Absolute measurement of II for sulphur-35 beta-rays, Radiation Research 7, 567 (1957).

[16] A. S. Penfold and J. E. Leiss, Phys. Rev. 114, 1332 (1959).

[17] A. S. Penfold and J. E. Leiss, Analysis of photo cross sections, Physics Research Lab., Univ. of Illinois, Champaign, Ill. (May, 1958).

[18] For energies below $10 \mathrm{Mev}$, aluminum absorption coefficients from reference [14] were used. At energies between 10 and $100 \mathrm{Mev}$, the coefficients used came from J. M. Wyckoff and H. W. Koch, Phys. Rev. 117, 1261 (1960). These latter were extrapolated to $170 \mathrm{Mev}$.

[19] J. S. Pruitt, A. Allisy, G. Joyet, W. Pohlit, M. Tubiana, and C. Zupančič, Transfer of NBS High Energr Calibrations to European Betatron Laboratories, J. Research NBS 66c, 107 (1962). 




\section{THE NATIONAL BUREAU OF STANDARDS}

The scope of activities of the National Bureau of Standards at its major laboratories in Washington, D.C., and Boulder, Colorado, is suggested in the following listing of the divisions and sections engaged in technical work. In general, each section carries out specialized research, development, and engineering in the field indicated by its title. A brief description of the activities, and of the resultant publications, appears on the inside of the front cover.

\section{WASHINGTON, D.C.}

Electricity. Resistance and Reactance. Electrochemistry. Electrical Instruments. Magnetic Measurements. Dielectrics. High Voltage.

Metrology. Photometry and Colorimetry. Refractometry. Photographic Research. Length. Engineering Metrology. Mass and Scale. Volumetry and Densimetry.

Heat. Temperature Physics. Heat Measurements. Cryogenic Physics. Equation of State. Statistical Physics. Radiation Physics. X-ray. Radioactivity. Radiation Theory. High Energy Radiation. Radiological Equipment. Nucleonic Instrumentation. Neutron Physics.

Analytical and Inorganic Chemistry. Pure Substances. Spectrochemistry. Solution Chemistry. Standard Reference Materials. Applied Analytical Research.

Mechanics. Sound. Pressure and Vacuum. Fluid Mechanics. Engineering Mechanics. Rheology. Combustion Controls.

Polymers. Macromolecules: Synthesis and Structure. Polymer Chemistry. Polymer Physics. Polymer Characterization. Polymer Evaluation and Testing. Applied Polymer Standards and Research. Dental Research.

Metallurgy. Engineering Metallurgy. Microscopy and Diffraction. Metal Reactions. Metal Physics. Electrolysis and Metal Deposition.

Inorganic Solids. Engineering Ceramics. Glass. Solid state chemistry. Crystal Growth. Physical Properties. Crystallography.

Building Research. Structural Engineering. Fire Research. Mechanical Systems. Organic Building Materials. Codes and Safety Standards. Heat Transfer. Inorganic Building Materials. Metallic Building Materials.

Applied Mathematics. Numerical Analysis. Computation. Statistical Engineering. Mathematical Physics. Operations Research.

Data Processing Systems. Components and Techniques. Computer Technology. Measurements Automation. Engineering Applications. Systems Analysis.

Atomic Physics. Spectroscopy. Infrared Spectroscopy. Solid State Physics. Electron Physics. Atomic Physics. Instrumentation. Engineering Electronics. Electron Devices. Electronic Instrumentation. Mechanical Instruments. Basic Instrumentation.

Physical Chemistry. Thermochemistry. Surface Chemistry. Organic Chemistry. Molecular Spectroscopy. Molecular Kinetics. Mass Spectrometry.

Office of Weights and Measures.

BOULDER, COLO.

Cryogenic Engineering. Cryogenic Equipment. Cryogenic Processes. Properties of Materials. Cryogenic Technical Services.

\section{CENTRAL RADIO PROPAGATION LABORATORY}

Ionosphere Research and Propagation. Low Frequency and Very Low Frequency Research. Ionosphere Research. Prediction Services. Sun-Earth Relationslips. Field Engineering. Radio Warning Services. Vertical Soundings Research.

Radio Propagation Engineering. Data Reduction Instrumentation. Radio Noise. Tropospheric Measurements. Tropospheric Analysis. Propagation-Terrain Effects. Radio-Meteorology. Lower Atmosphere Physics.

Radio Systems. Applied Electromagnetic Theory. High Frequency and Very High Frequency Research. Modulation Research. Antenna Research. Navigation Systems.

Upper Atmosphere and Space Physics. Upper Atmosphere and Plasma Physics. Ionosphere and Exosphere Scatter. Airglow and Aurora. Ionospheric Radio Astronomy.

\section{RADIO STANDARDS LABORATORY}

Radio Physics. Radio Broadcast Service. Radio and Microwave Materials. Atomic Frequency and Time-Interval Standards. Millimeter-Wave Research.

Circuit Standards. High Frequency Electrical Standards. Microwave Circuit Standards. Electronic Calibration Center. 







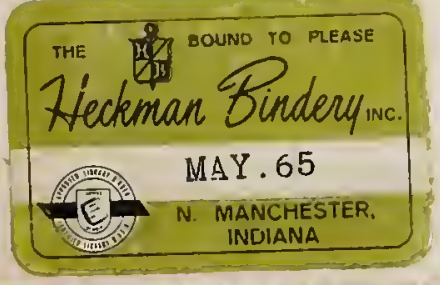


